MATHEMATICS OF COMPUTATION

Volume 76, Number 257, January 2007, Pages 115-136

S $0025-5718(06) 01886-2$

Article electronically published on September 15, 2006

\title{
STABILIZED FINITE ELEMENT METHOD BASED ON THE CRANK-NICOLSON EXTRAPOLATION SCHEME FOR THE TIME-DEPENDENT NAVIER-STOKES EQUATIONS
}

\author{
YINNIAN HE AND WEIWEI SUN
}

\begin{abstract}
This paper provides an error analysis for the Crank-Nicolson extrapolation scheme of time discretization applied to the spatially discrete stabilized finite element approximation of the two-dimensional time-dependent Navier-Stokes problem, where the finite element space pair $\left(X_{h}, M_{h}\right)$ for the approximation $\left(u_{h}^{n}, p_{h}^{n}\right)$ of the velocity $u$ and the pressure $p$ is constructed by the low-order finite element: the $Q_{1}-P_{0}$ quadrilateral element or the $P_{1}-P_{0}$ triangle element with mesh size $h$. Error estimates of the numerical solution $\left(u_{h}^{n}, p_{h}^{n}\right)$ to the exact solution $\left(u\left(t_{n}\right), p\left(t_{n}\right)\right)$ with $t_{n} \in(0, T]$ are derived.
\end{abstract}

\section{INTRODUCTION}

In a primitive variable formulation for solving the Stokes equations and the Navier-Stokes equations, the importance of ensuring the compatibility of discrete velocity and pressure by satisfying the so-called inf-sup condition is widely understood. In particular, it is well known that the simplest conforming low-order elements, such as the $P_{1}-P_{0}$ (linear velocity, constant pressure) triangular element and the $Q_{1}-P_{0}$ (bilinear velocity, constant pressure) quadrilateral element are not stable. During the last two decades there has been a rapid development in practical stabilization techniques for the $P_{1}-P_{0}$ element and the $Q_{1}-P_{0}$ element for solving the Stokes problem. For this purpose a local "macroelement condition" and some energy methods have been used. The use of such a macroelement condition as a mean of verifying the (Babuška-Brezzi) inf-sup condition is a standard technique (see, for example, Girault and Raviart [18]); the basic idea was first introduced by Boland and Nicolaides [8, and independently by Stenberg [43. The stabilized mixed finite element approximation under consideration is based on the combination of the standard variational formulation of the Stokes problem and the bilinear form including a jump operator in pressure. The discrete velocity $u_{h}$ and the pressure $p_{h}$ are chosen from finite element subspaces $X_{h}$ and $M_{h}$ of the Sobolev spaces $X$ and $M$ defined in Section 2, related to conforming low-order elements like the $P_{1}-P_{0}$ triangular element, or the $Q_{1}-P_{0}$ quadrilateral element,

Received by the editor November 22, 2004 and, in revised form, September 2, 2005.

2000 Mathematics Subject Classification. Primary 35L70; Secondary 65N30, 76D06.

Key words and phrases. Navier-Stokes problem, stabilized finite element, Crank-Nicolson extrapolation scheme.

The first author was supported in part by the NSF of the People's Republic of China (10371095).

The second author was supported in part by the Research Grants Council of the Hong Kong Special Administrative Region, People's Republic of China (Project No. City U 102103). 
which do not possess the properties required by the inf-sup condition. Recently, Kechkar and Silvester [33, 42, Kay and Silvester [32], Norburn and Silvester [36] and Silvester and Wathen [4] pursued some interesting work on both mathematical analysis and numerical tests of locally stabilized mixed finite element methods for the Stokes problem. Their work has also been extended to the Navier-Stokes problem and other related problems, (see, e.g., [26] and [21]), and some numerical analysis and tests of the stabilized finite element method for the stationary Navier-Stokes equations were provided by $\mathrm{He}$ et al. in 24.

The viscous incompressible Navier-Stokes equations with zero boundary conditions are one of the fundamental systems modelling fluid motion. The mathematical theory of these equations and their numerical solution are an important field of research. Here our aim is to solve the following time-dependent viscous incompressible Navier-Stokes problem:

$$
\left\{\begin{array}{l}
u_{t}-\nu \Delta u+(u \cdot \nabla) u+\nabla p=f, \operatorname{div} u=0,(x, t) \in \Omega \times(0, T] ; \\
u(x, 0)=u_{0}(x), x \in \Omega ;\left.u(x, t)\right|_{\Gamma}=0, t \in[0, T],
\end{array}\right.
$$

in a bounded two-dimensional domain with some appropriate assumptions stated in Section 2, where $u=u(x, t)=\left(u_{1}(x, t), u_{2}(x, t)\right)$ represents the velocity vector of a viscous incompressible fluid, $p=p(x, t)$ the pressure, $f=f(x, t)$ the prescribed body force, $u_{0}(x)$ the initial velocity, $\nu>0$ the viscosity and $T>0$ a finite time.

For the usual spatial discretization, i.e., time-continuous approximations, the finite element space pair $\left(X_{h}, M_{h}\right)$ needs to satisfy some appropriate approximate properties and the compatibility properties required by the inf-sup condition (see Heywood and Rannacher [27]), where $0<h<1$ is the mesh size. This means that the finite element space pair $\left(X_{h}, M_{h}\right)$ needs to be established by a more complex element than the $P_{1}-P_{0}$ element or the $Q_{1}-P_{0}$ element [3], [18], 27]. We assume that the data $\left(u_{0}, f\right)$ satisfy the assumption:

(A1): $u_{0} \in H^{2}(\Omega)^{2} \cap H_{0}^{1}(\Omega)^{2}$ with $\operatorname{div} u_{0}=0$ and $f, f_{t}, f_{t t} \in L^{\infty}\left(0, T ; L^{2}(\Omega)^{2}\right)$ with

$$
\left\|u_{0}\right\|_{2}+\sup _{t \in[0, T]}\left\{\|f(t)\|_{0}+\left\|f_{t}(t)\right\|_{0}+\left\|f_{t t}(t)\right\|_{0}\right\}<\infty .
$$

Then the spatial discrete solution $\left(u_{h}(t), p_{h}(t)\right)$ satisfies the error following estimates 27:

$$
\begin{aligned}
\left\|u(t)-u_{h}(t)\right\|_{0} & +h\left\|u(t)-u_{h}(t)\right\|_{1}+h \sigma^{1 / 2}(t)\left\|p(t)-p_{h}(t)\right\|_{0} \\
& \leq \kappa h^{2}, 0 \leq t \leq T,
\end{aligned}
$$

where $\sigma(t)=\min \{1, t\}$ and $\kappa>0$ is a general constant depending on the data $\left(\nu, \Omega, u_{0}, f, T\right)$ which may have different values at its different occurrences. For fully discrete approximations, the discrete solution $\left(u_{h}^{n}, p_{h}^{n}\right)$ based on the CrankNicolson scheme, in which the viscous term and the nonlinear term are discretized implicitly, satisfies the error estimates [28]

$$
\sigma\left(t_{m}\right)\left\|u_{h}\left(t_{m}\right)-u_{h}^{m}\right\|_{0} \leq \kappa \tau^{2}, \quad \sigma^{3 / 2}\left(t_{m}\right)\left\|p_{h}\left(t_{m}\right)-p_{h}^{m}\right\|_{0} \leq \kappa \tau,
$$

for all $t_{m}=m \tau \in(0, T]$, where $\tau \leq \kappa_{0}$ is the time step size, and $\kappa_{0}$ some fixed value depending on the data $\left(\nu, \Omega, u_{0}, f, T\right)$.

It is noted that the factors $\sigma^{s}\left(t_{n}\right)$ with $s=\frac{1}{2}, 1, \frac{3}{2}$ that appeared in (1.2)-(1.3) are due to the nonsmoothness of the time derivatives of the velocity $u$ and pressure $p$ at $t=0$. 
For the usual time discretization, i.e., spatial-continuous approximations, Shen 40. proposed a second-order projection scheme, in which the viscous term and the nonlinear term are treated implicitly and the pressure term explicitly. Guermond and Shen [19] studied a velocity-correction projection scheme for the linearized Navier-Stokes equations. The semi-discrete solution $\left(u^{n}, p^{n}\right)$ satisfies the error estimates

$$
\begin{gathered}
\left(\tau \sum_{n=n_{0}}^{m}\left\|u\left(t_{n}\right)-u^{n}\right\|_{0}^{2}\right)^{1 / 2} \leq \kappa \tau^{2},\left\|u\left(t_{m}\right)-u^{m}\right\|_{0} \leq \kappa \tau^{3 / 2}, \\
\left\|u\left(t_{m}\right)-u^{m}\right\|_{1}+\left\|p\left(t_{m}\right)-p^{m}\right\|_{0} \leq \kappa \tau,
\end{gathered}
$$

for all $t_{m}=m \tau \in\left(t_{n_{0}}, T\right]$ under the assumption (A1), where $0<t_{n_{0}}<T$ is a fixed time.

Moreover, a second-order time characteristics and a spatial discretization of the $P_{k}-P_{k^{\prime}}$ finite element type for the Navier-Stokes equations in the $d$-dimensional domain was presented by Boukir, Maday, Métivet and Razafindrakoto [9], and the $H^{1}$-error estimate is given by

$$
\left(\tau \sum_{n=1}^{m}\left\|p\left(t_{n}\right)-p_{h}^{n}\right\|_{0}^{2}\right)^{1 / 2}+\left\|u\left(t_{m}\right)-u_{h}^{m}\right\|_{1} \leq \kappa\left(\tau^{2}+h^{k}+h^{k^{\prime}+1}\right)
$$

for all $t_{m}=m \tau \in\left(t_{n_{0}}, T\right]$ under some stronger regularity assumption of the exact solution $(u(t), p(t))$ and the stability condition $\tau h^{-d / 6} \leq \kappa_{0}$ with $d=2,3$.

For simplicity of notation, we confine our attention to the $Q_{1}-P_{0}$ quadrilateral element and the $P_{1}-P_{0}$ triangle element. Let $\tau_{h}$ be a partition (triangles or quadrilaterals) of $\bar{\Omega}$ with mesh size $h$, assumed to be uniformly regular in the usual sense. Here the finite element space pair $\left(X_{h}, M_{h}\right)$ does not posses the compatibility properties required by the inf-sup condition. An earlier paper 26] dealt mainly with spatial discretization (time continuous approximations) and a later paper [21] studied a fully discrete stabilized finite element approximation, in which time is discretized by the backward Euler semi-implicit scheme with the time step $0<\tau<$ 1.

Assume that the initial velocity $u_{0} \in H_{0}^{1}(\Omega)^{2}$ with $\operatorname{div} u_{0}=0$ and $f, f_{t} \in$ $L^{\infty}\left(0, T ; L^{2}(\Omega)^{2}\right)$, He et al. [25] have proved that the spatial discrete solution $\left(u_{h}(t)\right.$, $\left.p_{h}(t)\right)$ satisfies the error estimates [26]

$$
\begin{aligned}
\sigma^{1 / 2}(t)\left\|u(t)-u_{h}(t)\right\|_{0} & +h \sigma^{1 / 2}(t)\left\|u(t)-u_{h}(t)\right\|_{1}+h \sigma(t)\left\|p(t)-p_{h}(t)\right\|_{0} \\
& \leq \kappa h^{2}, \quad 0 \leq t \leq T,
\end{aligned}
$$

while the fully discrete solution $\left(u_{h}^{n}, p_{h}^{n}\right)$ based on the backward Euler semi-implicit scheme satisfies the error estimates

$$
\begin{aligned}
\sigma^{1 / 2}\left(t_{m}\right)\left\|u\left(t_{m}\right)-u_{h}^{m}\right\|_{0} & \leq \kappa\left(h^{2}+\tau\right), \\
\sigma^{1 / 2}\left(t_{m}\right)\left\|u\left(t_{m}\right)-u_{h}^{m}\right\|_{1}+\sigma\left(t_{m}\right)\left\|p_{h}\left(t_{m}\right)-p_{h}^{m}\right\|_{0} & \leq \kappa\left(h+\tau^{1 / 2}\right),
\end{aligned}
$$

(see He [21]) for all $t_{m}=m \tau \in(0, T]$ and $\tau|\log h|^{1 / 2} \leq \kappa_{0}$.

This paper continues our analysis of the stabilized mixed finite element method based on the $Q_{1}-P_{0}$ quadrilateral element and the $P_{1}-P_{0}$ triangle element [26. 21 for solving the two-dimensional time-dependent Navier-Stokes equations with respect to the data $\left(u_{0}, f\right)$ satisfying the assumption $(\mathbf{A 1})$. We consider the second order fully discrete scheme based on the Crank-Nicolson extrapolation scheme in 
which we use an implicit scheme for the viscous and pressure terms and a semiimplicit scheme for the nonlinear term. The discrete solution $\left(u_{h}^{n}, p_{h}^{n}\right)$ satisfies the error estimates

$$
\begin{aligned}
\left\|u\left(t_{m}\right)-u_{h}^{m}\right\|_{0} & \leq \kappa\left(h^{2}+\tau^{3 / 2}\right) \\
\left\|u\left(t_{m}\right)-u_{h}^{m}\right\|_{1} & \leq\left(h+\tau^{3 / 4}\right), \sigma^{1 / 2}\left(t_{m}\right)\left\|\bar{p}\left(t_{m}\right)-\bar{p}_{h}^{m}\right\|_{0} \leq \kappa\left(h+\tau^{3 / 4}\right)
\end{aligned}
$$

for all $t_{m} \in(0, T]$, where $I_{\tau}=\left\{t_{m}\right\}_{0}^{N}$ is a given set in the interval $[0, T]$ with a time step size $\tau=\max _{1 \leq m \leq N}\left(t_{m}-t_{m-1}\right)$, and

$$
\bar{p}_{h}^{m}=\frac{1}{2}\left(p_{h}^{m}+p_{h}^{m-1}\right), \bar{p}\left(t_{m}\right)=\frac{1}{2}\left(p\left(t_{m}\right)+p\left(t_{m-1}\right)\right) .
$$

The contents of this paper are divided into sections as follows. In Section 2, the abstract functional setting of the Navier-Stokes problem is given with some basic statements. Stabilized finite element approximations are recalled in Section 3. Some key technical lemmas and known results are provided in Section 4 . The fully discrete stabilized finite element method with the Crank-Nicolson extrapolation scheme and the corresponding fully discrete duality problem are considered in section Section 5 . The $L^{2}$ - and $H^{1}$-error estimates for the discrete velocity and $L^{2}$-error estimate for the discrete pressure are derived in Section 6.

\section{Functional Setting of the Navier-Stokes Problem}

For the mathematical setting of problem (1.1), first we introduce the Hilbert spaces

$$
X=H_{0}^{1}(\Omega)^{2}, \quad Y=L^{2}(\Omega)^{2}, \quad M=L_{0}^{2}(\Omega)=\left\{q \in L^{2}(\Omega) ; \int_{\Omega} q d x=0\right\} .
$$

The spaces $L^{2}(\Omega)^{m}, m=1,2,4$, are endowed with the $L^{2}$-scalar product and $L^{2}$ norm denoted by $(\cdot, \cdot)$ and $\|\cdot\|_{0}$. The space $X$ is equipped with its equivalent scalar product $(\nabla u, \nabla v)$ and norm $|u|_{1}=\|\nabla u\|_{0}$. Next, let the closed subset $V$ of $X$ be given by

$$
V=\{v \in X ; \operatorname{div} v=0\},
$$

and denote by $H$ the closed subset of $Y$; i.e.,

$$
H=\left\{v \in Y ; \operatorname{div} v=0,\left.v \cdot n\right|_{\partial \Omega}=0\right\} .
$$

We refer the readers to [1, 2, 6, 7, 18, 27, 45, for more detail on these spaces. We also denote the Laplace operator by $A=-\Delta$ and denote the Stokes operator by $\bar{A}=-P \Delta$, where $P$ is the $L^{2}$-orthogonal projection of $Y$ onto $H$.

As mentioned above, we need a further assumption on $\Omega$ :

(A2) Assume that $\Omega$ is smooth so that the unique solution $(v, q) \in(X, M)$ of the steady Stokes problem

$$
-\Delta v+\nabla q=g, \operatorname{div} v=0 \quad \text { in } \Omega,\left.v\right|_{\partial \Omega}=0,
$$

for prescribed $g \in Y$ exists and satisfies

$$
\|v\|_{2}+\|q\|_{1} \leq c\|g\|_{0},
$$

where $c>0$ is a generic constant depending on $\Omega$ and $\nu$ which may stand for a different value at its different occurrences, and $\|\cdot\|_{i}$ denotes the usual norm of Sobolev spaces $H^{i}(\Omega)^{m} ; i=0,1,2, m=1,2,4$. 
We remark that the validity of assumption (A2) is known (see [18, 27, 31, 30, 45]) if $\partial \Omega$ is of $C^{2}$, or if $\Omega$ is a two-dimensional convex polygon. From assumption (A2), it is known [1, 27, 34] that

$$
\begin{aligned}
\|A v\|_{0}^{2} & \leq\|v\|_{2}^{2} \leq c\|\bar{A} v\|_{0}^{2}, v \in H^{2}(\Omega)^{2} \cap V \\
\|v\|_{0} & \leq \gamma_{0}|v|_{1}, v \in X,|v|_{1} \leq \gamma_{0}\|v\|_{2} \leq c\|A v\|_{0}, v \in H^{2}(\Omega)^{2} \cap X,
\end{aligned}
$$

where $\gamma_{0}$ is positive constant depending only on $\Omega$.

We define the continuous bilinear forms $a(\cdot, \cdot)$ and $d(\cdot, \cdot)$ on $X \times X$ and $X \times M$, respectively, by

$$
\begin{gathered}
a(u, v)=\nu(\nabla u, \nabla v), u, v \in X, \\
d(v, q)=-(v, \nabla q)=(q, \operatorname{div} v), v \in X, q \in M,
\end{gathered}
$$

and a trilinear form on $X \times X \times X$ by

$$
\begin{aligned}
b(u, v, w) & =((u \cdot \nabla) v, w)+\frac{1}{2}((\operatorname{div} u) v, w) \\
& =\frac{1}{2}((u \cdot \nabla) v, w)-\frac{1}{2}((u \cdot \nabla) w, v), \forall u, v, w \in X .
\end{aligned}
$$

With the above notations, the variational formulation of problem (1.1) reads as follows. Find $(u, p) \in(X, M), t \in(0, T]$ such that for all $(v, q) \in(X, M)$,

$$
\begin{aligned}
\left(u_{t}, v\right)+a(u, v)-d(v, p)+d(u, q)+b(u, u, v) & =(f, v), \\
u(0) & =u_{0} .
\end{aligned}
$$

A simple modification to the regularity argument given in 29, 27, allows us to obtain the following regularity results.

Theorem 2.1. Assume that assumptions (A1) and (A2) are valid. Then the problem (2.3)-(2.4) admits a unique solution $(u, p)$ satisfying the regularity results

$$
\begin{array}{r}
\|u(t)\|_{2}^{2}+\|p(t)\|_{1}^{2}+\left\|u_{t}(t)\right\|_{0}^{2}+\int_{0}^{t}\left\|u_{t}\right\|_{1}^{2} d s \leq \kappa, \\
\sigma(t)\left\|u_{t}(t)\right\|_{1}^{2}+\int_{0}^{t} \sigma(s)\left(\left\|u_{t t}\right\|_{0}^{2}+\left\|u_{t}\right\|_{2}^{2}+\left\|p_{t}\right\|_{1}^{2}\right) d s \leq \kappa, \\
\sigma^{2}(t)\left(\left\|u_{t}(t)\right\|_{2}^{2}+\left\|p_{t}(t)\right\|_{1}^{2}+\left\|u_{t t}(t)\right\|_{0}^{2}\right)+\int_{0}^{t} \sigma^{2}(s)\left\|u_{t t}\right\|_{1}^{2} d s \leq \kappa, \\
\sigma^{3}(t)\left\|u_{t t}(t)\right\|_{1}^{2}+\int_{0}^{t} \sigma^{3}(s)\left(\left\|u_{t t t}\right\|_{0}^{2}+\left\|u_{t t}\right\|_{2}^{2}+\left\|p_{t t}\right\|_{1}^{2}\right) d s \leq \kappa,
\end{array}
$$

for all $t \in[0, T]$.

\section{Stabilized finite element approximation}

Let $h>0$ be a real positive parameter. The finite element subspace $\left(X_{h}, M_{h}\right)$ of $(X, M)$ is characterized by $\tau_{h}=\tau_{h}(\Omega)$, a partitioning of $\bar{\Omega}$ into triangles $K$ or quadrilaterals $K$, assumed to be uniformly regular as $h \rightarrow 0$. For further details, the reader can refer to Ciarlet 13 and Girault and Raviart [18. The mesh parameter $h$ is given by $h=\max \left\{h_{K}\right\}$, and the set of all interelement boundaries will be denoted by $\Gamma_{h}$.

Finite element subspaces of interest in this paper are defined by setting

$$
R_{1}(K)=\left\{\begin{array}{l}
P_{1}(K) \text { if } K \text { is triangular, } \\
Q_{1}(K) \text { if } K \text { is quadrilateral }
\end{array}\right.
$$


giving the continuous piecewise (bi)linear velocity subspace

$$
X_{h}=\left\{v \in C^{0}(\bar{\Omega})^{2} \cap X ;\left.v_{i}\right|_{K} \in R_{1}(K), i=1,2, K \in \tau_{h}\right\},
$$

and the piecewise constant pressure subspace

$$
M_{h}=\left\{q \in M ;\left.q\right|_{K} \in P_{0}(K), K \in \tau_{h}\right\} .
$$

Note that neither of these methods are stable in the standard Babuška-Brezzi sense; the $P_{1}-P_{0}$ triangle "locks" on regular grids (since there are more discrete incompressibility constraints than velocity degrees of freedom), and the $Q_{1}-P_{0}$ quadrilateral is one example of unstable mixed methods, as elucidated by Sani et al. in 38 .

In order to define a locally stabilized formulation of the time-dependent NavierStokes problem, we introduce a macroelement partitioning $\Lambda_{h}$ as follows. Given any subdivision $\tau_{h}$, a macroelement partitioning $\Lambda_{h}$ may be defined such that each macroelement $\mathcal{K}$ is a connected set of adjoining elements from $\tau_{h}$. Every element $K$ must lie in exactly one macroelement, which implies that macroelements do not overlap. For each $\mathcal{K}$, the set of interelement edges which are strictly in the interior of $\mathcal{K}$ will be denoted by $\Gamma_{\mathcal{K}}$. The length of edge $e \in \Gamma_{\mathcal{K}}$ is denoted by $h_{e}$.

With these additional definitions a locally stabilized discrete formulation of the problem (2.3)-(2.4) can be stated as follows.

Definition 3.1. Locally Stabilized Formulation. Find $\left(u_{h}, p_{h}\right) \in\left(X_{h}, M_{h}\right)$ such that for all $t \in(0, T]$ and $\left(v_{h}, q_{h}\right) \in\left(X_{h}, M_{h}\right)$,

$$
\begin{aligned}
\left(u_{h t}, v_{h}\right)+\mathcal{B}_{h}\left(\left(u_{h}, p_{h}\right) ;\left(v_{h}, q_{h}\right)\right)+b\left(u_{h}, u_{h}, v_{h}\right) & =\left(f, v_{h}\right), \\
u_{h}(0) & =u_{0 h},
\end{aligned}
$$

where $u_{0 h} \in X_{h}$ is an approximation of $u_{0}$ and

$$
\mathcal{B}_{h}\left(\left(u_{h}, p_{h}\right) ;\left(v_{h}, q_{h}\right)\right)=\mathcal{B}\left(\left(u_{h}, p_{h}\right) ;\left(v_{h}, q_{h}\right)\right)+\beta \mathcal{C}_{h}\left(p_{h}, q_{h}\right),
$$

for all $\left(u_{h}, p_{h}\right),\left(v_{h}, q_{h}\right) \in\left(X_{h}, M_{h}\right)$, here

$$
\begin{gathered}
\mathcal{B}((u, p) ;(v, q))=a(u, v)-d(v, p)+d(u, q) \forall(u, p),(v, q) \in(X, M), \\
\mathcal{C}_{h}(p, q)=\sum_{\mathcal{K} \in \Lambda_{h}} \sum_{e \in \Gamma_{\mathcal{K}}} h_{e} \int_{e}[p]_{e}[q]_{e} d s,
\end{gathered}
$$

for all $p, q$ in the algebraic sum $H^{1}(\Omega)+M_{h},[\cdot]_{e}$ is the jump operator across $e \in \Gamma_{\mathcal{K}}$ and $\beta>0$ is the local stabilization parameter.

A general framework for analyzing the locally stabilized formulation (3.2)-(3.3) can be developed using the notion of an equivalent class of macroelements. As in Stenberg [4], each equivalence class, denoted by $\mathcal{E}_{\hat{\mathcal{K}}}$, contains macroelements which are topologically equivalent to a reference macroelement $\hat{\mathcal{K}}$. To illustrate the idea, two practical examples of locally stabilized mixed approximations are given below.

Example 3.1. The first example is the standard $Q_{1}-P_{0}$ approximation pair. A locally stabilized formulation $(3.2)-(3.3)$ can be constructed in this case, if $\tau_{h}$ is such that the elements $K$ can be grouped into $2 \times 2$ macroelements

$$
\mathcal{K}=\left\{K_{1}, K_{2}, K_{3}, K_{4}\right\}
$$

with the reference macroelement

$$
\hat{\mathcal{K}}=\left\{\hat{K}_{1}, \hat{K}_{2}, \hat{K}_{3}, \hat{K}_{4}\right\} .
$$


An obvious way of constructing such a partitioning in practice is to form the grid $\tau_{h}$ by uniformly refining a coarse grid $\Lambda_{h}$, such as by joining the midedge points.

Example 3.2. The triangular $P_{1}-P_{0}$ approximation pair can be stabilized similarly if the partitioning $\tau_{h}$ is constructed such that the elements can be grouped into disjoint macroelements, all consisting of four elements.

The following properties are classical (see [7, 13, 47, 48]):

$$
\left|v_{h}\right|_{1} \leq c h^{-1}\left\|v_{h}\right\|_{0}, v_{h} \in X_{h} .
$$

The following stability results of this mixed method for the macroelement partitions defined above were formally established by Kay and Silvester [32] and Kechkar and Silvester [33.

Theorem 3.2. Given a stabilization parameter $\beta \geq \beta_{0}>0$, suppose that every macroelement $\mathcal{K} \in \Lambda_{h}$ belongs to one of the equivalence classes $\mathcal{E}_{\hat{\mathcal{K}}}$, and that the following macroelement connectivity condition is valid: for any two neighboring macroelements $\mathcal{K}_{1}$ and $\mathcal{K}_{2}$ with $\int_{\mathcal{K}_{1} \cap \mathcal{K}_{2}} d s \neq 0$ there exists $v \in X_{h}$ such that

$$
\operatorname{supp} v \subset \mathcal{K}_{1} \cup \mathcal{K}_{2} \quad \text { and } \quad \int_{\mathcal{K}_{1} \cap \mathcal{K}_{2}} v \cdot n d s \neq 0 .
$$

Then,

$$
\left|\mathcal{C}_{h}(p, q)\right| \leq c \sum_{K \in \tau_{h}}\left(\int_{K}\left(\|p\|_{0}^{2}+h^{2}\|\nabla p\|_{0}^{2}\right) d x\right)^{1 / 2}\left(\int_{K}\left(\|q\|_{0}^{2}+h^{2}\|\nabla q\|_{0}^{2}\right) d x\right)^{1 / 2}
$$

for all $p, q \in H^{1}(\Omega)+M_{h}$, and

$$
\alpha\left(\left|u_{h}\right|_{1}+\left\|p_{h}\right\|_{0}\right) \leq \sup _{\left(v_{h}, q_{h}\right) \in\left(X_{h}, M_{h}\right)} \frac{\mathcal{B}_{h}\left(\left(u_{h}, p_{h}\right) ;\left(v_{h}, q_{h}\right)\right)}{\left\|v_{h}\right\|+\left|q_{h}\right|},
$$

for all $\left(u_{h}, p_{h}\right) \in\left(X_{h}, M_{h}\right)$, and

$(3.8) \mathcal{C}_{h}\left(p, q_{h}\right)=0, \mathcal{C}_{h}\left(p_{h}, q\right)=0, \mathcal{C}_{h}(p, q)=0, \forall p, q \in H^{1}(\Omega), p_{h}, q_{h} \in M_{h}$,

where $\alpha>0$ is a constant independent of $h$ and $\beta$, and $\beta_{0}$ is some fixed positive constant and $n$ is the unit outward normal vector.

\section{TECHNICAL PRELIMINARIES}

This section considers preliminary estimates which will be very useful in error estimates of the finite element solution $\left(u_{h}, p_{h}\right)$.

With the statements in Section 3, a discrete analogue $A_{h}=-\Delta_{h}$ of the Laplacian operator $A=-\Delta$ is defined through the condition that $\left(-\Delta_{h} u_{h}, v_{h}\right)=\left(\left(u_{h}, v_{h}\right)\right)$ for all $u_{h}, v_{h} \in X_{h}$. The operator $A_{h}: X_{h} \rightarrow X_{h}$ is invertible, with its inverse denoted $A_{h}^{-1}$. Since $A_{h}^{-1}$ is self-adjoint and positive definite, we may define "discrete" Sobolev norms on $X_{h}$, of any order $r \in R$, by setting

$$
\left|v_{h}\right|_{r}=\left\|A_{h}^{r / 2} v_{h}\right\|_{0}, \quad \forall v_{h} \in X_{h} .
$$

These norms will be assumed to have various properties similar to their continuous counterparts, an assumption that implicitly imposes conditions on the structure of the spaces $X_{h}$ and $M_{h}$. In particular, it holds that

$$
\left|v_{h}\right|_{0}=\left\|v_{h}\right\|_{0}, \quad\left|v_{h}\right|_{1}=\left\|\nabla v_{h}\right\|_{0}, \quad\left|v_{h}\right|_{2}=\left\|A_{h} v_{h}\right\|_{0}, \quad \forall v_{h} \in X_{h} .
$$


By the way, we derive from (2.2) that

$$
\left\|v_{h}\right\|_{0} \leq \gamma_{0}\left\|\nabla v_{h}\right\|_{0}, \quad\left\|\nabla v_{h}\right\|_{0} \leq \gamma_{0}\left\|A_{h} v_{h}\right\|_{0}, \quad \forall v_{h} \in V_{h},
$$

where $\gamma_{0}>0$ is a constant depending only on $\Omega$.

Moreover, we define the discrete gradient operator $\nabla_{h}$ for $q_{h} \in M_{h}$ as

$$
\left(v_{h}, \nabla_{h} q_{h}\right)=-d\left(v_{h}, q_{h}\right), \forall v_{h} \in X_{h} .
$$

Now, by using a slightly modified argument on the estimates of the trilinear form $b$ provided in $21,22,23,27,28,29$, we can obtain the following results on $b$.

Lemma 4.1. The trilinear form $b$ satisfies the estimates

$$
\begin{aligned}
b\left(u_{h}, v_{h}, w_{h}\right) & =-b\left(u_{h}, v_{h}, w_{h}\right), \\
\left|b\left(u_{h}, v_{h}, w_{h}\right)\right| & +\left|b\left(v_{h}, u_{h}, w_{h}\right)\right|+\left|b\left(w_{h}, u_{h}, v_{h}\right)\right| \\
& \leq \frac{c_{0}}{2}\left\|u_{h}\right\|_{0}^{1 / 2}\left|u_{h}\right|_{1}^{1 / 2}\left|v_{h}\right|_{1}\left\|w_{h}\right\|_{0}^{1 / 2}\left|w_{h}\right|_{1}^{1 / 2} \\
& +\frac{c_{0}}{2}\left|u_{h}\right|_{1}\left\|v_{h}\right\|_{0}^{1 / 2}\left|v_{h}\right|_{1}^{1 / 2}\left\|w_{h}\right\|_{0}^{1 / 2}\left|w_{h}\right|_{1}^{1 / 2}, \\
\left|b\left(u_{h}, v_{h}, w_{h}\right)\right| & +\left|b\left(v_{h}, u_{h}, w_{h}\right)\right|+\left|b\left(w_{h}, u_{h}, v_{h}\right)\right| \\
& \leq \frac{c_{0}}{2}\left\|A_{h} v_{h}\right\|_{0}^{1 / 2}\left\|v_{h}\right\|_{1}^{1 / 2}\left\|u_{h}\right\|_{0}^{1 / 2}\left\|u_{h}\right\|_{1}^{1 / 2}\left\|w_{h}\right\|_{0} \\
& +\frac{c_{0}}{2}\left\|A_{h} v_{h}\right\|_{0}^{1 / 2}\left\|v_{h}\right\|_{0}^{1 / 2}\left\|u_{h}\right\|_{1}\left\|w_{h}\right\|_{0},
\end{aligned}
$$

for all $u_{h}, v_{h}, w_{h} \in X_{h}$, where $c_{0}>0$ is a constant depending only on $\Omega$.

In order to derive the error estimates of the finite element solution $\left(u_{h}, p_{h}\right)$, we also define the Galerkin projection $\left(R_{h}, Q_{h}\right):(X, Y) \rightarrow\left(X_{h}, M_{h}\right)$ by requiring

$$
\begin{array}{r}
\mathcal{B}_{h}\left(\left(R_{h}(u, p), Q_{h}(u, p)\right) ;\left(v_{h}, q_{h}\right)\right)=\mathcal{B}\left((u, p) ;\left(v_{h}, q_{h}\right)\right), \\
\forall(u, p) \in(X, M),\left(v_{h}, q_{h}\right) \in\left(X_{h}, M_{h}\right) .
\end{array}
$$

Note that, due to Theorem 3.2, $\left(R_{h}, Q_{h}\right)$ is well defined and satisfies the approximate properties 24

$$
\left\|R_{h}(u, p)-u\right\|_{0}+h\left(\left|R_{h}(u, p)-u\right|_{1}+\left\|Q_{h}(u, p)-p\right\|_{0}\right) \leq c h^{2}\left(\|u\|_{2}+\|p\|_{1}\right),
$$

for all $(u, p) \in\left(H^{2}(\Omega)^{2} \cap X, H^{1}(\Omega) \cap M\right)$.

Moreover, we need to introduce the following $L^{2}$-orthogonal projection $P_{h}$ : $L^{2}(\Omega)^{2} \rightarrow X_{h}$ defined by

$$
\left(P_{h} v, v_{h}\right)=\left(v, v_{h}\right), v \in L^{2}(\Omega)^{2}, v_{h} \in X_{h} .
$$

Using some slight modifications of the literature [26, 27, we can obtain the following error estimates.

Theorem 4.2. Assume the assumptions of Theorems 2.1 and 3.2 are valid and set $\left(u_{0 h}, p_{0 h}\right)=\left(R_{h}\left(u_{0}, p_{0}\right), Q_{h}\left(u_{0}, p_{0}\right)\right)$. Then $\left(u_{h}, p_{h}\right)$ satisfies

$$
\left(\int_{0}^{t} \sigma(s)\left|u_{t}-u_{h t}\right|_{1}^{2} d s\right)^{1 / 2} \leq \kappa h,
$$

for all $t \in(0, T]$, where $p_{0}=\lim _{t \rightarrow 0} p(t) \in H^{1}(\Omega) \cap M$. 
Since our error analysis for the time discretization depends heavily on some regularity estimates of the semi-discrete solution $\left(u_{h}, p_{h}\right)$, we will provide the following regularity results.

Theorem 4.3. Under the assumptions of Theorems 4.2, the finite element solution $\left(u_{h}, p_{h}\right)$ satisfies the regularities

$$
\begin{gathered}
\int_{0}^{t}\left(\left\|A_{h}^{-1}\left(u_{h t t}+P_{h} \nabla_{h} p_{h t}\right)\right\|_{0}^{2}+\left\|u_{h t}\right\|_{0}^{2}+\left\|A_{h} u_{h}\right\|_{0}^{2}\right) d s \\
+\nu\left|u_{h}(t)\right|_{1}^{2}+\beta \mathcal{C}_{h}\left(p_{h}(t) a, p_{h}(t)\right) \leq \kappa, \\
\int_{0}^{t}\left(\left\|A_{h}^{-1 / 2}\left(u_{h t t}+P_{h} \nabla_{h} p_{h t}\right)\right\|_{0}^{2}+\nu\left|u_{h t}\right|_{1}^{2}+\beta \mathcal{C}_{h}\left(p_{h t}, p_{h t}\right)\right) d s \\
+\left(\left\|u_{h t}(t)\right\|_{0}^{2}+\left\|\nabla_{h} p_{h}(t)\right\|_{0}^{2}+\left\|A_{h} u_{h}(t)\right\|_{0}^{2}\right) \leq \kappa, \\
\int_{0}^{t} \sigma(s)\left(\left\|u_{h t t}\right\|_{0}^{2}+\left\|P_{h} \nabla_{h} p_{h t}\right\|_{0}^{2}+\left\|A_{h} u_{h t}\right\|_{0}^{2}\right) d s \leq \kappa, \\
\int_{0}^{t} \sigma(s)\left\|A_{h}^{-1}\left(u_{h t t t}+P_{h} \nabla_{h} p_{h t t}\right)\right\|_{0}^{2} d s \\
+\sigma(t)\left(\nu\left|u_{h t}(t)\right|_{1}^{2}+\beta \mathcal{C}_{h}\left(p_{h t}(t), p_{h t}(t)\right)\right) \leq \kappa, \\
\int_{0}^{t} \sigma^{2}(s)\left(\left\|A_{h}^{-1 / 2}\left(u_{h t t t}+P_{h} \nabla_{h} p_{h t t}\right)\right\|_{0}^{2}+\nu\left|u_{h t t}\right|_{1}^{2}+\beta \mathcal{C}_{h}\left(p_{h t t}, p_{h t t}\right)\right) d s \\
+\sigma^{2}(t)\left\|u_{h t t}(t)\right\|_{0}^{2} \leq \kappa, \\
\int_{0}^{t} \sigma^{3}(s)\left(\left\|u_{h t t t}\right\|_{0}^{2}+\left\|P_{h} \nabla_{h} p_{h t t}\right\|_{0}^{2}+\left\|A_{h} u_{h t t}\right\|_{0}^{2}\right) d s \leq \kappa,
\end{gathered}
$$

for all $t \in[0, T]$.

Proof. The proof is by a fairly standard energy argument. Hereafter, we will make frequent use of (4.1)-(4.4) without explicit mention.

First, differentiating (3.2) with respect to $t$ results in the equations

$$
\begin{aligned}
\left(u_{h t t}+P_{h} \nabla_{h} p_{h t}, v_{h}\right) & +a\left(u_{h t}, v_{h}\right)+d\left(u_{h t}, q_{h}\right)+\beta \mathcal{C}_{h}\left(p_{h t}, q_{h}\right) \\
& +b_{t}\left(u_{h}, u_{h}, v_{h}\right)=\left(f_{t}, v_{h}\right), \\
\left(u_{h t t t}+P_{h} \nabla_{h} p_{h t t}, v_{h}\right) & +a\left(u_{h t t}, v_{h}\right)+d\left(u_{h t t}, q_{h}\right)+\beta \mathcal{C}_{h}\left(p_{h t t}, q_{h}\right) \\
& +b_{t t}\left(u_{h}, u_{h}, v_{h}\right)=\left(f_{t t}, v_{h}\right) .
\end{aligned}
$$

If we take $q_{h}=0$ in (4.15) -(4.16), a simple calculation yields

$$
\begin{gathered}
\left.\int_{0}^{t}\left\|A_{h}^{-i / 2}\left(u_{h t t}+P_{h} \nabla_{h} p_{h t}\right)\right\|_{0}^{2} d s \leq c \int_{0}^{t}\left\|A_{h}^{1-i / 2} u_{h t}\right\|_{0}^{2}\left(1+\left|u_{h}\right|_{1}^{2}\right)+\left\|f_{t}\right\|_{0}^{2}\right) d s, \\
\int_{0}^{t} \sigma^{3-i}(s)\left\|A_{h}^{-i / 2}\left(u_{h t t t}+P_{h} \nabla_{h} p_{h t t}\right)\right\|_{0}^{2} d s \leq c \int_{0}^{t} \sigma^{3-i}(s)\left\|A_{h}^{1-i / 2} u_{h t}\right\|_{0}^{2}\left|u_{h t}\right|_{1}^{2} d s \\
+c \int_{0}^{t}\left(\sigma^{3-i}(s)\left\|A_{h}^{1-i / 2} u_{h t t}\right\|_{0}^{2}\left(1+\left|u_{h}\right|_{1}^{2}\right)+\left\|f_{t t}\right\|_{0}^{2}\right) d s,
\end{gathered}
$$

for $i=2,1,0$.

Next, using (3.4), we obtain

$$
\left\|A_{h} u_{h}\right\|_{0}=\sup _{v_{h} \in X_{h}} \frac{\left|\left(A_{h} u_{h}, v_{h}\right)\right|}{\left\|v_{h}\right\|_{0}} \leq\left(c h^{-1}\left|u-u_{h}\right|_{1}+\|A u\|_{0}\right),
$$


for all $u_{h} \in X_{h}$ and $u \in X$. Hence, we derive from Theorems 2.1 and 4.2 that

$$
\left\|A_{h} u_{h}(t)\right\|_{0}^{2} \leq c\left(h^{-2}\left|u(t)-u_{h}(t)\right|_{1}^{2}+\|A u(t)\|_{0}^{2}\right) \leq \kappa, \forall 0 \leq t \leq T .
$$

Now, by recalling [26, 21], we have

$$
\nu\left|u_{h}(t)\right|_{1}^{2}+\beta \mathcal{C}_{h}\left(p_{h}(t), p_{h}(t)\right)+\int_{0}^{t}\left\|u_{h t}\right\|_{0}^{2} d s \leq \kappa, \forall 0 \leq t \leq T .
$$

Taking $\left(v_{h}, q_{h}\right)=\left(u_{h t}, p_{h t}\right)$ in (4.15) and using (2.3) and (4.1)-(4.3), we obtain

$$
\begin{aligned}
\frac{1}{2} \frac{d}{d t}\left\|u_{h t}\right\|_{0}^{2} & +\nu\left|u_{h t}\right|_{1}^{2}+\beta \mathcal{C}_{h}\left(p_{h t}, p_{h t}\right)+b\left(u_{h t}, u_{h}, u_{h t}\right)=\left(f_{t}, u_{h t}\right), \\
\left|b\left(u_{h t}, u_{h}, u_{h t}\right)\right| & \leq c|| u_{h t}\left\|_{0}\left|u_{h t}\right|_{1}\right\| A_{h} u_{h}\left\|_{0} \leq \frac{\nu}{4}\left|u_{h t}\right|_{1}^{2}+c\right\| A_{h} u_{h}\left\|_{0}^{2}\right\| u_{h t} \|_{0}^{2}, \\
\left(f_{t}, u_{h t}\right) & \leq \frac{\nu}{4}\left|u_{h t}\right|_{1}^{2}+c\left\|f_{t}\right\|_{0}^{2} .
\end{aligned}
$$

From the definition of $\left(u_{h}(0), p_{h}(0)\right)=\left(R_{h}\left(u_{0}, p_{0}\right), Q_{h}\left(u_{0}, p_{0}\right)\right)$, it holds that

$$
\left(u_{h t}(0), v_{h}\right)-\nu\left(\Delta u_{0}, v_{h}\right)+\left(v_{h}, \nabla p_{0}\right)+b\left(u_{h}(0), u_{h}(0), v_{h}\right)=\left(f(0), v_{h}\right),
$$

which with (4.1) and (4.2) yield

$$
\left\|u_{h t}(0)\right\|_{0} \leq c\left\|u_{0}\right\|_{2}+\left\|p_{0}\right\|_{1}+c\left\|A_{h} u_{h}(0)\right\|_{0}\left|u_{h}(0)\right|_{1}+\|f(0)\|_{0} .
$$

Now we integrate (4.22) and use (4.23)-(4.24), (4.26) and (4.20)-(4.21) to obtain

$$
\left\|u_{h t}(t)\right\|_{0}^{2}+\int_{0}^{t}\left(\nu\left|u_{h t}\right|_{1}^{2}+\beta \mathcal{C}_{h}\left(p_{h t}, p_{h t}\right)\right) d s \leq \kappa, 0 \leq t \leq T .
$$

Combining (4.17) with (4.20)-(4.21) and (4.27) and using (3.2) yields (4.9)-(4.10).

Furthermore, we derive from (4.19), (4.8), (4.2) and (2.6) that

$$
\int_{0}^{t} \sigma(s)\left\|A_{h} u_{h t}\right\|_{0}^{2} d s \leq c \int_{0}^{t} \sigma(s)\left(h^{-2}\left|u_{t}-u_{h t}\right|_{1}^{2}+\left\|A u_{t}\right\|_{0}^{2}\right) d s \leq \kappa,
$$

for all $0 \leq t \leq T$, which (4.9) and (4.17) with $i=0$ yield

$$
\int_{0}^{t} \sigma(s)\left\|u_{h t t}+\nabla_{h} p_{h t}\right\|_{0}^{2} d s \leq \kappa, \forall 0 \leq t \leq T .
$$

Moreover, we derive from (4.15) that

$$
\begin{aligned}
\left(u_{h t t}, v_{h}\right) & +a\left(u_{h t}, v_{h}\right)-d\left(v_{h}, p_{h t}\right)+d\left(u_{h t t}, q_{h}\right)+\beta \mathcal{C}_{h}\left(p_{h t t}, q_{h}\right) \\
& +b\left(u_{h t}, u_{h}, v_{h}\right)+b\left(u_{h}, u_{h t}, v_{h}\right)=\left(f_{t}, v_{h}\right) .
\end{aligned}
$$

By taking $\left(v_{h}, q_{h}\right)=\sigma(t)\left(u_{h t t}, p_{h t}\right)$ in (4.30), we obtain

$$
\begin{aligned}
\sigma(t)\left\|u_{h t t}\right\|_{0}^{2} & +\frac{1}{2} \frac{d}{d t}\left(\sigma(t) \nu\left|u_{h t}\right|_{1}^{2}+\sigma(t) \beta \mathcal{C}_{h}\left(p_{h t}, p_{h t}\right)\right) \\
& +\sigma(t) b\left(u_{h t}, u_{h}, u_{h t t}\right)+\sigma(t) b\left(u_{h}, u_{h t}, u_{h t t}\right) \\
& =\frac{1}{2} \frac{d}{d t} \sigma(t)\left(\nu\left|u_{h t}\right|_{1}^{2}+\beta \mathcal{C}_{h}\left(p_{h t}, p_{h t}\right)\right)+\sigma(t)\left(f_{t}, u_{h t t}\right) .
\end{aligned}
$$


Using (4.1)-(4.3), we have

$$
\begin{aligned}
\sigma(t)\left|b\left(u_{h t}, u_{h}, u_{h t t}\right)\right| & +\sigma(t)\left|b\left(u_{h}, u_{h t}, u_{h t t}\right)\right| \\
& \leq c \sigma(t)\left|u_{h t}\right|_{1}\left\|A_{h} u_{h}\right\|_{0}\left\|u_{h t t}\right\|_{0}^{2} \\
& \leq \frac{1}{4} \sigma(t)\left\|u_{h t t}\right\|_{0}^{2}+c \sigma(t)\left|u_{h t}\right|_{1}^{2}\left\|A_{h} u_{h}\right\|_{0}^{2}, \\
\sigma(t)\left|\left(f_{t}, u_{h t t}\right)\right| & \leq \frac{1}{4} \sigma(t)\left\|u_{h t t}\right\|_{0}^{2}+c\left\|f_{t}\right\|_{0}^{2} .
\end{aligned}
$$

Combining these inequalities with (4.31) yields

$$
\begin{aligned}
\sigma(t)\left\|u_{h t t}\right\|_{0}^{2} & +\frac{d}{d t}\left(\sigma(t) \nu\left|u_{h t}\right|_{1}^{2}+\sigma(t) \beta \mathcal{C}_{h}\left(p_{h t}, p_{h t}\right)\right) \\
& \leq \nu\left|u_{h t}\right|_{1}^{2}+\beta \mathcal{C}_{h}\left(p_{h t}, p_{h t}\right)+c \sigma(t)\left|u_{h t}\right|_{1}^{2}\left\|A_{h} u_{h}\right\|_{0}^{2}+\left\|f_{t}\right\|_{0}^{2} .
\end{aligned}
$$

In view of (4.10), there exists a sequence $\epsilon_{n} \rightarrow 0$ such that

$$
\sigma\left(\epsilon_{n}\right) \nu\left|u_{h t}\left(\epsilon_{n}\right)\right|_{1}^{2}+\sigma\left(\epsilon_{n}\right) \beta \mathcal{C}_{h}\left(p_{h t}\left(\epsilon_{n}\right), p_{h t}\left(\epsilon_{n}\right)\right) \rightarrow 0 .
$$

Therefore, integrating (4.32) from $\epsilon_{n}$ to $t$ and letting $\epsilon_{n} \rightarrow 0$, one finds

$$
\begin{aligned}
\int_{0}^{t} \sigma(s) & \left\|u_{h t t}\right\|_{0}^{2} d s+\sigma(t) \nu\left|u_{h t}\right|_{1}^{2}+\sigma(t) \beta \mathcal{C}_{h}\left(p_{h t}(t), p_{h t}(t)\right) \\
\leq & \int_{0}^{t}\left(\nu\left|u_{h t}\right|_{1}^{2}+\beta \mathcal{C}_{h}\left(p_{h t}, p_{h t}\right)\right) d s \\
& \quad+c \int_{0}^{t} \sigma(s)\left|u_{h t}\right|_{1}^{2}\left\|A_{h} u_{h}\right\|_{0}^{2} d s+c \int_{0}^{t}\left\|f_{t}\right\|_{0}^{2} d s
\end{aligned}
$$

Applying the Gronwall lemma to (4.33) and using (4.10), we obtain

$$
\int_{0}^{t} \sigma(s)\left\|u_{h t t}\right\|_{0}^{2} d s+\sigma(t) \nu\left|u_{h t}(t)\right|_{1}^{2}+\sigma(t) \beta \mathcal{C}_{h}\left(p_{h t}(t), p_{h t}(t)\right) \leq k, 0 \leq t \leq T .
$$

Combining (4.34) with (4.28)-(4.29) and using (4.18) with $i=2$ yields (4.11)-(4.12).

Similarly, we can prove (4.13)-(4.14) by using (3.2), (3.4), (4.1)-(4.4) and (4.9)(4.12).

Also, we will introduce some discrete versions of the Gronwall lemma by a slightly improved argument used in [16, 39.

Lemma 4.4. Let $C, \tau$ and $a_{n}, b_{n}, d_{n}$, for integers $n \geq n_{1}$, be nonnegative numbers such that

$$
a_{m}+\tau \sum_{n=n_{1}}^{m} b_{n} \leq \tau \sum_{n=n_{1}}^{m-1} a_{n} d_{n}+C, \forall m \geq n_{1}
$$

Then,

$$
a_{m}+\tau \sum_{n=n_{1}}^{m} b_{n} \leq \exp \left(\tau \sum_{n=n_{1}}^{m-1} d_{n}\right) C, \forall m \geq n_{1}
$$




\section{Fully Discrete StABilized Finite ElEMENT MEthoD}

In this section we consider the time discretization of the stabilized finite element approximation. Let $t_{n}=n \tau$, where $\tau=\frac{T}{N}$ and $N$ is an integer. The CrankNicolson extrapolation scheme applied to the stabilized finite element approximation is to determine the series $\left\{u_{h}^{n}\right\}_{n=1}^{N} \subset X_{h},\left\{p_{h}^{n}\right\}_{n=1}^{N} \subset M_{h}$ as the solution of the recursive linear equation

$$
\left(d_{t} u_{h}^{n}, v_{h}\right)+\mathcal{B}_{h}\left(\left(\bar{u}_{h}^{n}, \bar{p}_{h}^{n}\right) ;\left(v_{h}, q_{h}\right)\right)+b\left(\phi\left(u_{h}^{n}\right), \bar{u}_{h}^{n}, v_{h}\right)=\left(\bar{f}\left(t_{n}\right), v_{h}\right),
$$

for all $\left(v_{h}, q_{h}\right) \in\left(X_{h}, M_{h}\right)$ for the initial value $\left(u_{h}^{0}, p_{h}^{0}\right)=\left(u_{0 h}, p_{0 h}\right)$. Here and after, we define a small time step size $\tau_{0}=T^{-1} \tau^{3 / 2}$ on time interval $\left(0, \tau^{1 / 2}\right]$ and a large time step size $\tau=\frac{T}{n_{0}}$ on $\left[\tau^{1 / 2}, T\right]$ for some fixed integer $n_{0}$, where

$$
\begin{gathered}
\tau_{0} n_{0}=\tau^{1 / 2}, N=n_{0}+\frac{T-\tau^{1 / 2}}{\tau}=\frac{2 T}{\tau}-\tau^{-1 / 2}, \\
d_{t} u_{h}^{n}=\frac{1}{k}\left(u_{h}^{n}-u_{h}^{n-1}\right), k=\tau_{0} \text { as } 1 \leq n \leq n_{0}, k=\tau \text { as } n_{0}+1 \leq n \leq N, \\
\phi\left(u_{h}^{0}\right)=\phi\left(u_{h}^{1}\right)=u_{h}^{0}, \phi\left(u_{h}^{n}\right)=\frac{3}{2} u_{h}^{n-1}-\frac{1}{2} u_{h}^{n-2}, 2 \leq n \leq N, \\
\bar{u}_{h}^{n}=\frac{1}{2}\left(u_{h}^{n}+u_{h}^{n-1}\right), \bar{u}_{h}\left(t_{n}\right)=\frac{1}{2}\left(u_{h}\left(t_{n}\right)+u_{h}\left(t_{n-1}\right)\right) .
\end{gathered}
$$

From the definition of $\phi$, we find that the Crank-Nicolson extrapolation scheme is an implicit scheme for the viscous and pressure terms and a semi-implicit scheme for the nonlinear term.

In order to analyze the discretization errors $\left(e_{h}^{n}, \bar{\mu}^{n}\right)=\left(u_{h}\left(t_{n}\right)-u_{h}^{n}, \bar{p}_{h}\left(t_{n}\right)-\bar{p}_{h}^{n}\right)$ with $\left(e_{h}^{0}, \mu_{h}^{0}\right)=(0,0)$, we deduce from (3.2) that

$$
\begin{gathered}
\frac{1}{k}\left(u_{h}\left(t_{n}\right)-u_{h}\left(t_{n-1}\right), v_{h}\right)+\frac{1}{k} \int_{t_{n-1}}^{t_{n}} \mathcal{B}_{h}\left(\left(u_{h}(t), p_{h}(t)\right) ;\left(v_{h}, q_{h}\right)\right) d t \\
+\frac{1}{k} \int_{t_{n-1}}^{t_{n}} b\left(u_{h}(t), u_{h}(t), v_{h}\right) d t=\frac{1}{k} \int_{t_{n-1}}^{t_{n}}\left(f(t), v_{h}\right) d t
\end{gathered}
$$

for all $\left(v_{h}, q_{h}\right) \in\left(X_{h}, M_{h}\right)$. Subtracting (5.1) from (5.2) and using the following formulas

$$
\begin{gathered}
d\left(\bar{u}_{h}\left(t_{n}\right), q_{h}\right)+\beta \mathcal{C}_{h}\left(\bar{p}_{h}\left(t_{n}\right), q_{h}\right)=0 \\
\frac{1}{k} \int_{t_{n-1}}^{t_{n}}\left(d\left(u_{h}(t), q_{h}\right)+\beta \mathcal{C}_{h}\left(p_{h}(t), q_{h}\right)\right) d t=0 \\
\bar{\phi}\left(t_{n}\right)-\frac{1}{k} \int_{t_{n-1}}^{t_{n}} \phi(t) d t=\frac{1}{2 k} \int_{t_{n-1}}^{t_{n}}\left(t_{n}-t\right)\left(t-t_{n-1}\right) \phi_{t t}(t) d t
\end{gathered}
$$

for all $\phi \in H^{2}\left(t_{n-1}, t_{n} ; F\right)$ for some Hilbert space $F$, then using (3.2), results in

$$
\begin{gathered}
\left(d_{t} e_{h}^{n}, v_{h}\right)+\mathcal{B}_{h}\left(\left(\bar{e}_{h}^{n}, \tilde{\mu}_{h}^{n}\right) ;\left(v_{h}, q_{h}\right)\right)+b\left(\phi\left(e_{h}^{n}\right), \bar{u}_{h}\left(t_{n}\right), v_{h}\right)+\beta\left(\phi\left(u_{h}^{n}\right), \bar{e}_{h}^{n}, v_{h}\right) \\
=\left(\tilde{E}_{n}, v_{h}\right)-\frac{\beta}{2 k} \int_{t_{n-1}}^{t_{n}}\left(t_{n}-t\right)\left(t-t_{n-1}\right) \mathcal{C}_{h}\left(p_{h t t}, q_{h}\right) d t
\end{gathered}
$$

for all $\left(v_{h}, q_{h}\right) \in\left(X_{h}, M_{h}\right)$, and

$$
\begin{aligned}
& \left(d_{t} e_{h}^{n}, v_{h}\right)+\mathcal{B}_{h}\left(\left(\bar{e}_{h}^{n}, \bar{\mu}_{h}^{n}\right) ;\left(v_{h}, q_{h}\right)\right)+b\left(\phi\left(e_{h}^{n}\right), \bar{u}_{h}\left(t_{n}\right), v_{h}\right)+b\left(\phi\left(u_{h}^{n}\right), \bar{e}_{h}^{n}, v_{h}\right) \\
& \quad=\left(E_{n}, v_{h}\right)
\end{aligned}
$$


for all $\left(v_{h}, q_{h}\right) \in\left(X_{h}, M_{h}\right)$, where $\tilde{\mu}_{h}^{n}=\frac{1}{k} \int_{t_{n-1}}^{t_{n}} p_{h}(t) d t-\bar{p}_{h}^{n}$ and

$$
\begin{aligned}
\left(\tilde{E}_{1}, v_{h}\right)= & -\frac{1}{2 k} \int_{t_{0}}^{t_{1}}\left(t_{1}-t\right)\left(t-t_{0}\right)\left(u_{h t t t}+P_{h} \nabla_{h} p_{h t t}, v_{h}\right) d t \\
& -\frac{1}{2} b\left(\int_{t_{0}}^{t_{1}} u_{h t} d t, u_{h}\left(t_{1}\right), v_{h}\right), \\
\left(\tilde{E}_{n}, v_{h}\right)= & -\frac{1}{2 k} \int_{t_{n-1}}^{t_{n}}\left(t_{n}-t\right)\left(t-t_{n-1}\right)\left(u_{h t t t}+P_{h} \nabla_{h} p_{h t t}, v_{h}\right) d t \\
& -\frac{1}{2} b\left(\int_{t_{n-1}}^{t_{n}}\left(t_{n}-t\right) u_{h t t} d t-\int_{t_{n-2}}^{t_{n-1}}\left(t-t_{n-2}\right) u_{h t t} d t, \bar{u}_{h}\left(t_{n}\right), v_{h}\right) \\
& -\frac{1}{4} b\left(\int_{t_{n-1}}^{t_{n}} u_{h t} d t, \int_{t_{n-1}}^{t_{n}} u_{h t} d t, v_{h}\right),
\end{aligned}
$$

for all $2 \leq n \leq N$, and

$$
\begin{aligned}
\left(E_{1}, v_{h}\right)= & -\frac{1}{2 k} \int_{t_{0}}^{t_{1}}\left(t_{1}-t\right)\left(t-t_{0}\right)\left(u_{h t t t}, v_{h}\right) d t \\
& -\frac{1}{2} b\left(\int_{t_{0}}^{t_{1}} u_{h t} d t, u_{h}\left(t_{1}\right), v_{h}\right) \\
\left(E_{n}, v_{h}\right)= & -\frac{1}{2 k} \int_{t_{n-1}}^{t_{n}}\left(t_{n}-t\right)\left(t-t_{n-1}\right)\left(u_{h t t t}, v_{h}\right) d t \\
& -\frac{1}{2} b\left(\int_{t_{n-1}}^{t_{n}}\left(t_{n}-t\right) u_{h t t} d t-\int_{t_{n-2}}^{t_{n-1}}\left(t-t_{n-2}\right) u_{h t t} d t, \bar{u}_{h}\left(t_{n}\right), v_{h}\right) \\
& -\frac{1}{4} b\left(\int_{t_{n-1}}^{t_{n}} u_{h t} d t, \int_{t_{n-1}}^{t_{n}} u_{h t} d t, v_{h}\right),
\end{aligned}
$$

for all $2 \leq n \leq N$.

In order to provide the bound of the error $\left(e_{h}^{n}, \bar{\mu}_{h}^{n}\right)$, we need to provide the bound of $\tilde{E}_{n}$ and $E_{n}$.

Lemma 5.1. Under the assumptions of Theorem 4.2, it holds that

$$
\begin{gathered}
\tau_{0} \sum_{n=1}^{n_{0}} \sigma^{i}\left(t_{n}\right)\left\|A_{h}^{-1 / 2} P_{h} \tilde{E}_{n}\right\|_{0}^{2} \leq \kappa \tau_{0}^{i+2}, \quad i=0,1, \\
\tau \sum_{n=n_{0}+1}^{N}\left\|A_{h}^{-1 / 2} P_{h} \tilde{E}_{n}\right\|_{0}^{2} \leq \kappa \tau^{3}, \\
\tau_{0} \sum_{n=1}^{n_{0}} \sigma^{i}\left(t_{n}\right)\left\|P_{h} E_{n}\right\|_{0}^{2} \leq \kappa \tau_{0}^{i+1}, \quad i=0,1, \\
\tau \sum_{n=n_{0}+1}^{N} \sigma^{i}\left(t_{n}\right)\left\|P_{h} E_{n}\right\|_{0}^{2} \leq \kappa \tau^{5 / 2+i / 2}, \quad i=0,1 .
\end{gathered}
$$


Proof. In this proof for brevity we will make frequent use of (4.1)-(4.4) and the facts

$$
\begin{aligned}
\sigma\left(t_{n}\right) & \leq \sigma\left(t_{n-1}\right)+\tau_{0}, \quad 1 \leq n \leq n_{0}, \\
\sigma\left(t_{n-1}\right) & \leq 2 \sigma\left(t_{n-2}\right), \quad n_{0}+1 \leq n \leq N,
\end{aligned}
$$

without explicit mention in this section.

First, we derive from (5.6) and the Schwarz inequality that

$$
\begin{aligned}
&\left\|A_{h}^{-1 / 2} P_{h} \tilde{E}_{n}\right\|_{0}=\sup _{v_{h} \in X_{h}} \frac{\left|\left(\tilde{E}_{n}, v_{h}\right)\right|}{\left\|A_{h}^{1 / 2} v_{h}\right\|_{0}} \\
& \leq \frac{1}{k} \int_{t_{n-1}}^{t_{n}}\left(t_{n}-t\right)\left(t-t_{n-1}\right)\left\|A_{h}^{-1 / 2}\left(u_{h t t t}+P_{h} \nabla_{h} p_{h t t}\right)\right\|_{0} d t \\
&+\kappa\left(\int_{t_{n-1}}^{t_{n}}\left(t_{n}-t\right)\left|u_{h t t}\right|_{1} d t+\int_{t_{n-2}}^{t_{n-1}}\left(t-t_{n-2}\right)\left|u_{h t t}\right|_{1} d t\right) \\
&+\kappa\left(\int_{t_{n-1}}^{t_{n}}\left|u_{h t}\right|_{1} d t\right)^{2} \\
& \leq \kappa k^{-1 / 2}\left(\int_{t_{n-1}}^{t_{n}}\left(t_{n}-t\right)^{2} k^{2}\right. \\
&\left.\quad \times\left(\left\|A_{h}^{-1 / 2}\left(u_{h t t t}+P_{h} \nabla_{h} p_{h t t}\right)\right\|_{0}^{2}+\left|u_{h t t}\right|_{1}^{2}\right) d t\right)^{1 / 2} \\
& \quad+\kappa k^{-1 / 2}\left(\int_{t_{n-2}}^{t_{n-1}}\left(t-t_{n-2}\right)^{2} k^{2}\left|u_{h t t}\right|_{1}^{2} d t\right)^{1 / 2}+\kappa k \int_{t_{n-1}}^{t_{n}}\left|u_{h t}\right|_{1}^{2} d t
\end{aligned}
$$

with $k=\tau_{0}$ for $1 \leq n \leq n_{0}$ and $k=\tau$ for $n_{0}+1 \leq n \leq N$. Similarly, we deduce from (5.5) that

$$
\begin{aligned}
\left\|A_{h}^{-1 / 2} P_{h} \tilde{E}_{1}\right\|_{0} \leq & c_{0} \gamma_{0}\left\|A_{h} u_{h}\left(t_{1}\right)\right\|_{0} \sup _{t_{0} \leq t \leq t_{1}}\left\|u_{h t}(t)\right\|_{0} \tau_{0} \\
& +\kappa \tau_{0}^{1 / 2}\left(\int_{t_{0}}^{t_{1}} \sigma^{2}(t)\left\|A_{h}^{-1 / 2}\left(u_{h t t t}+P_{h} \nabla_{h} p_{h t t}\right)\right\|_{0}^{2} d t\right)^{1 / 2} .
\end{aligned}
$$

Thus, by using (5.13)-(5.14) and Theorem 4.3, we obtain

$$
\begin{aligned}
& \sigma^{i}\left(t_{n}\right)\left\|A_{h}^{-1 / 2} \tilde{E}_{n}\right\|_{0}^{2} \tau_{0} \\
& \leq \kappa \tau_{0}^{2+i} \int_{t_{n-1}}^{t_{n}}\left(\sigma^{2}(t)\left\|A_{h}^{-1 / 2}\left(u_{h t t t}+P_{h} \nabla_{h} p_{h t t}\right)\right\|_{0}^{2}+\left|u_{h t}\right|_{1}^{2}\right) d t \\
& \quad+\kappa \tau_{0}^{2+i} \int_{t_{n-2}}^{t_{n}} \sigma^{2}(t)\left|u_{h t t}\right|_{1}^{2} d t, 2 \leq n \leq n_{0}, i=0,1, \\
&\left\|A_{h}^{-1 / 2} \tilde{E}_{n}\right\|_{0}^{2} \tau \\
& \leq \kappa \tau^{4} \sigma^{-2}\left(t_{n-1}\right) \int_{t_{n-1}}^{t_{n}} \sigma^{2}(t)\left(\left\|A_{h}^{-1 / 2}\left(u_{h t t t}+P_{h} \nabla_{h} p_{h t t}\right)\right\|_{0}^{2}\right. \\
&\left.\quad+\left|u_{h t}\right|_{1}^{2}\right) d t+\kappa \tau^{4} \sigma^{-2}\left(t_{n-1}\right) \int_{t_{n-2}}^{t_{n}} \sigma^{2}(t)\left|u_{h t t}\right|_{1}^{2} d t,
\end{aligned}
$$

for all $n_{0}+1 \leq n \leq N$. Summing (5.16) from $n=2$ to $n=n_{0}$ and (5.17) from $n=n_{0}+1$ to $n=N$, respectively, using (5.15) and Theorem 4.3 and noting $\sigma^{-2}\left(t_{n-1}\right) \leq t_{n_{0}}^{-2}=\tau^{-1}$ for all $n_{0}+1 \leq n \leq N$, we have obtained (5.9) and (5.10) . 
Furthermore, we derive from (5.7)-(5.8) that

$$
\begin{aligned}
\left\|P_{h} E_{1}\right\|_{0}= & \sup _{v_{h} \in X_{h}} \frac{\left|\left(E_{1}, v_{h}\right)\right|}{\left\|v_{h}\right\|_{0}} \\
\leq & c_{0} \gamma_{0} \tau_{0}^{1 / 2}\left\|A_{h} u_{h}\left(t_{1}\right)\right\|_{0}\left(\int_{t_{0}}^{t_{1}}\left|u_{h t}(t)\right|_{1}^{2} d t\right)^{1 / 2} \\
& +2 \sup _{t_{0} \leq t \leq t_{1}}\left\|u_{h t}(t)\right\|_{0}, \\
\left\|P_{h} E_{n}\right\|_{0}= & \sup _{v_{h} \in X_{h}} \frac{\left|\left(E_{n}, v_{h}\right)\right|}{\left\|v_{h}\right\|_{0}} \\
\leq & k^{-1 / 2}\left(\int_{t_{n-1}}^{t_{n}}\left(t_{n}-t\right)^{2}\left(t-t_{n-1}\right)^{2}\left\|u_{h t t}\right\|_{0} d t\right)^{1 / 2}\left\|A_{h} \bar{u}_{h}\left(t_{n}\right)\right\|_{0} \\
& +c k^{-1 / 2}\left(\int_{t_{n-1}}^{t_{n}}\left(t_{n}-t\right)^{2} k^{2}\left|u_{h t t}\right|_{1}^{2} d t\right)^{1 / 2} \\
& +c k^{-1 / 2}\left(\int_{t_{n-2}}^{t_{n-1}}\left(t-t_{n-2}\right)^{2} k^{2}\left|u_{h t t}\right|_{1}^{2} d t\right)^{1 / 2}\left\|A_{h} \bar{u}_{h}\left(t_{n}\right)\right\|_{0} \\
& +c \kappa^{1 / 2}\left(\int_{t_{n-1}}^{t_{n}} k\left\|A_{h} u_{h t}\right\|_{0}^{2} d t\right)^{1 / 2}\left(\int_{t_{n-1}}^{t_{n}}\left|u_{h t}\right|_{1}^{2} d t\right)^{1 / 2},
\end{aligned}
$$

for all $2 \leq n \leq N$. Hence, we derive from (5.19), (5.13), and Theorem 4.3 that

$$
\begin{aligned}
\sigma^{i}\left(t_{n}\right)\left\|P_{h} E_{n}\right\|_{0}^{2} \tau_{0} \leq & \kappa \tau_{0}^{i+1} \int_{t_{n-1}}^{t_{n}}\left(\sigma^{3}(t)\left\|u_{h t t t}\right\|_{0}^{2}+\left|u_{h t}\right|_{1}^{2}\right) d t \\
& +\kappa \tau_{0}^{i+1} \int_{t_{n-2}}^{t_{n}} \sigma^{2}(t)\left|u_{h t t}\right|_{1}^{2} d t, \quad 2 \leq n \leq n_{0},
\end{aligned}
$$

$$
\begin{aligned}
\sigma^{i}\left(t_{n}\right)\left\|P_{h} E_{n}\right\|_{0}^{2} \tau \leq & \kappa \tau^{4} \sigma^{-3+i}\left(t_{n-1}\right) \int_{t_{n-1}}^{t_{n}}\left(\sigma^{3}(t)\left\|u_{h t t t}\right\|_{0}^{2}+\left|u_{h t}\right|_{1}^{2}\right) d t \\
& +\kappa \tau^{4} \sigma^{-3+i}\left(t_{n-1}\right) \int_{t_{n-2}}^{t_{n}} \sigma^{3}(t)\left|u_{h t t}\right|_{1}^{2} d t, \quad n_{0}+1 \leq n \leq N .
\end{aligned}
$$

Summing (5.20) from $n=2$ to $n=n_{0}$ and (5.21) from $n=n_{0}+1$ to $n=N$, respectively, using Theorem 4.3 and (5.18) and noting $\sigma^{-1}\left(t_{n-1}\right) \leq t_{n_{0}}^{-1} \leq \tau^{-1 / 2}$ for all $n_{0}+1 \leq n \leq N$, we arrive at (5.11) and (5.12).

\section{ERRor ANALYSIS}

In this section we will analyze the error $\left(e_{h}^{n}, \bar{\mu}_{h}^{n}\right)$. With the aid of Lemma 5.1. we shall obtain the following lower-order error estimates.

Lemma 6.1. Under the assumptions of Theorem 4.2, it holds that

$$
\begin{gathered}
\left\|e_{h}^{m}\right\|_{0}^{2}+\tau_{0} \sum_{n=1}^{m}\left(\nu\left|\bar{e}_{h}^{n}\right|_{1}^{2}+\beta \mathcal{C}_{h}\left(\tilde{\mu}_{h}^{n}, \tilde{\mu}_{h}^{n}\right)\right) \leq \kappa \tau_{0}^{2}, \quad 1 \leq m \leq n_{0}, \\
\left\|e_{h}^{m}\right\|_{0}^{2}+\tau \sum_{n=1}^{m}\left(\nu\left|\bar{e}_{h}^{n}\right|_{1}^{2}+\beta \mathcal{C}_{h}\left(\tilde{\mu}_{h}^{n}, \tilde{\mu}_{h}^{n}\right)\right) \leq \kappa \tau_{0}^{2}+\kappa \tau^{3}, \quad n_{0}+1 \leq m \leq N .
\end{gathered}
$$


Proof. First, we take $\left(v_{h}, q_{h}\right)=2\left(\bar{e}_{h}^{n}, \tilde{\mu}_{h}^{n}\right) k$ in (5.3) and use (4.1) (4.2) and (4.4), obtaining

$$
\begin{aligned}
\left\|e_{h}^{n}\right\|_{0}^{2}- & \left\|e_{h}^{n-1}\right\|_{0}^{2}+2 \nu\left|\bar{e}_{h}^{n}\right|_{1}^{2} k+2 \beta \mathcal{C}_{h}\left(\tilde{\mu}_{h}^{n}, \tilde{\mu}_{h}^{n}\right) k \\
= & -2 b\left(\phi\left(e_{h}^{n}\right), \bar{u}_{h}\left(t_{n}\right), \bar{e}_{h}^{n}\right) k+2\left(\tilde{E}_{n}, \bar{e}_{h}^{n}\right) k \\
& -\beta \int_{t_{n-1}}^{t_{n}}\left(t-t_{n}\right)\left(t-t_{n-1}\right) \mathcal{C}_{h}\left(p_{h t t}, \tilde{\mu}_{h}^{n}\right) d t \\
\leq & \nu\left|\bar{e}_{h}^{n}\right|_{1}^{2} k+\beta \mathcal{C}_{h}\left(\tilde{\mu}_{h}^{n}, \tilde{\mu}_{h}^{n}\right) k+4 \nu^{-1}\left\|A_{h}^{-1 / 2} P_{h} \tilde{E}_{n}\right\|_{0}^{2} k \\
& +4 \nu^{-1} c_{0}^{2} \gamma_{0}^{2}\left\|A_{h} \bar{u}_{h}\left(t_{n}\right)\right\|_{0}^{2}\left\|\phi\left(e_{h}^{n}\right)\right\|_{0}^{2} k \\
& +\beta \int_{t_{n-1}}^{t_{n}}\left(t-t_{n}\right)^{2}\left(t-t_{n-1}\right)^{2} \mathcal{C}_{h}\left(p_{h t t}, p_{h t t}\right) d t,
\end{aligned}
$$

for all $1 \leq n \leq N$ with $k=\tau_{0}$ for $1 \leq n \leq n_{0}$ and $k=\tau$ for $n_{0}+1 \leq n \leq N$. Summing (6.3) from $n=1$ to $n=m$ for $m \leq n_{0}$ and $n=n_{0}+1$ to $n=m$ for $n_{0}+1 \leq m \leq N$, respectively, noting $e_{h}^{0}=0, \sigma^{-2}\left(t_{n-1}\right) \leq \tau_{n_{0}}^{-2}=\tau^{-1}, n_{0}+1 \leq$ $n \leq N$ and using Lemma 5.1 and Theorem 4.3 we obtain

$$
\begin{aligned}
& \left\|e^{m}\right\|_{0}^{2}+\tau_{0} \sum_{n=1}^{m}\left(\nu\left|\bar{e}_{h}^{n}\right|_{1}^{2}+\beta \mathcal{C}_{h}\left(\tilde{\mu}_{h}^{n}, \tilde{\mu}_{h}^{n}\right)\right) \\
& \quad \leq \kappa \tau_{0}^{2}+\kappa \tau_{0} \sum_{n=1}^{m-1}\left\|e_{h}^{n}\right\|_{0}^{2}, \quad 1 \leq m \leq n_{0}, \\
& \left\|e^{m}\right\|_{0}^{2}+\tau \sum_{n=1}^{m}\left(\nu\left|\bar{e}_{h}^{n}\right|_{1}^{2}+\beta \mathcal{C}_{h}\left(\tilde{\mu}_{h}^{n}, \tilde{\mu}_{h}^{n}\right)\right) \\
& \quad \leq\left\|e_{h}^{n_{0}}\right\|_{0}^{2}+\kappa \tau^{3}+\kappa \tau \sum_{n=1}^{m-1}\left\|e_{h}^{n}\right\|_{0}^{2}, \quad n_{0}+1 \leq m \leq N .
\end{aligned}
$$

Applying Lemma 4.4) to (6.4) and (6.5), respectively, we arrive at (6.1) and (6.2).

Lemma 6.2. Under the assumptions of Theorem 4.2, the following estimates hold:

$$
\nu\left|e_{h}^{m}\right|_{1}^{2}+\beta \mathcal{C}_{h}\left(\mu_{h}^{m}, \mu_{h}^{m}\right)+\tau_{0} \sum_{n=1}^{m}\left\|d_{t} e_{h}^{n}\right\|_{0}^{2} \leq \kappa \tau_{0}, 1 \leq m \leq n_{0},
$$

$$
\nu\left|e_{h}^{m}\right|_{1}^{2}+\beta \mathcal{C}_{h}\left(\mu_{h}^{m}, \mu_{h}^{m}\right)+\tau \sum_{n=n_{0}+1}^{m}\left\|d_{t} e_{h}^{n}\right\|_{0}^{2} \leq \kappa \tau_{0}+\kappa \tau^{2}, n_{0}+1 \leq m \leq N,
$$

where $\mu^{0}=0, \mu^{n}=2 \bar{\mu}^{n}-\mu^{n-1}$.

Proof. In view of the fact

$$
d\left(e_{h}^{0}, q_{h}\right)+\beta \mathcal{C}_{h}\left(\mu_{h}^{0}, q_{h}\right)=0, \quad \forall q_{h} \in M_{h},
$$

we derive from (5.4) that

$$
\begin{aligned}
\left(d_{t} e_{h}^{n}, v_{h}\right)+a\left(\bar{e}_{h}^{n}, v_{h}\right)-d\left(v_{h}, \bar{\mu}_{h}^{n}\right)+d\left(d_{t} e_{h}^{n}, q_{h}\right)+\beta \mathcal{C}_{h}\left(d_{t} \mu_{h}^{n}, q_{h}\right) & \\
& +b\left(\phi\left(u_{h}^{n}\right), \bar{e}_{h}^{n}, v_{h}\right)+b\left(\phi\left(e_{h}^{n}\right), \bar{u}_{h}\left(t_{n}\right), v_{h}\right) \\
= & \left(E_{n}, v_{h}\right), \quad \forall\left(v_{h}, q_{h}\right) \in\left(X_{h}, M_{h}\right) .
\end{aligned}
$$


By setting $\left(v_{h}, q_{h}\right)=2\left(d_{t} e_{h}^{n}, \bar{\mu}_{h}^{n}\right) k$ in (6.8), we obtain

$$
\begin{aligned}
& 2\left\|d_{t} e_{h}^{n}\right\|_{0}^{2} k+\nu\left(\left|e_{h}^{n}\right|_{1}^{2}-\left|e_{h}^{n-1}\right|_{1}^{2}\right)+\beta\left(\mathcal{C}_{h}\left(\mu_{h}^{n}, \mu_{h}^{n}\right)-\mathcal{C}_{h}\left(\mu_{h}^{n-1}, \mu_{h}^{n-1}\right)\right) \\
& \quad+2 b\left(\phi\left(e_{h}^{n}\right), \bar{u}_{h}\left(t_{n}\right), d_{t} e_{h}^{n}\right) k+2 b\left(\phi\left(u_{h}\left(t_{n}\right)\right), \bar{e}_{h}^{n}, d_{t} e_{h}^{n}\right) k \\
& \quad-2 b\left(\phi\left(e_{h}^{n}\right), \bar{e}_{h}^{n}, d_{t} e_{h}^{n}\right) k=2\left(E_{n}, d_{t} e_{h}^{n}\right) k .
\end{aligned}
$$

Thus, it follows from (4.1)-(4.4), Theorem 4.3 and Lemma 6.1 that

$$
\begin{aligned}
& 2 \mid b(\left.\phi\left(e_{h}^{n}\right), \bar{u}_{h}\left(t_{n}\right), d_{t} e_{h}^{n}\right)|k+2| b\left(\phi\left(u_{h}\left(t_{n}\right)\right), \bar{e}_{h}^{n}, d_{t} e_{h}^{n}\right) \mid k \\
& \quad \leq 2 c_{0} \gamma_{0}\left(\left\|A_{h} \phi\left(u_{h}\left(t_{n}\right)\right)\right\|_{0}\left|\bar{e}_{h}^{n}\right|_{1}+\left\|A_{h} \bar{u}_{h}\left(t_{n}\right)\right\|_{0}\left|\phi\left(e_{h}^{n}\right)\right|_{1}\right)\left\|d_{t} e^{n}\right\|_{0} k \\
& \leq \frac{1}{2}\left\|d_{t} e^{n}\right\|_{0}^{2} k+\kappa\left(\left|e_{h}^{n-1}\right|_{1}^{2}+\left|e_{h}^{n-2}\right|_{1}^{2}+\left|\bar{e}_{h}^{n}\right|_{1}^{2}\right) k, \\
& 2\left|\left(E_{n}, d_{t} e_{h}^{n}\right)\right| k \leq \frac{1}{4}\left\|d_{t} e^{n}\right\|_{0}^{2} k+4\left\|P_{h} E_{n}\right\|_{0}^{2} k, \\
& 2\left|b\left(\phi\left(e_{h}^{n}\right), \bar{e}_{h}^{n}, d_{t} e_{h}^{n}\right)\right| k \leq c_{0}\left\|\phi\left(e_{h}^{n}\right)\right\|_{0}^{1 / 2}\left|\phi\left(e_{h}^{n}\right)\right|_{1}^{1 / 2}\left|\bar{e}_{h}^{n}\right|_{1}\left\|d_{t} e_{h}^{n}\right\|_{0}^{1 / 2}\left|d_{t} e_{h}^{n}\right|_{1}^{1 / 2} k \\
& \quad+\left.c_{0}\left\|\phi\left(e_{h}^{n}\right)\right\|_{0}^{1 / 2}\left|\phi\left(e_{h}^{n}\right)\right|_{1}^{1 / 2}\left|\bar{e}_{h}^{n} \|_{0}^{1 / 2}\right| \bar{e}_{h}^{n}\right|_{1} ^{1 / 2}\left|d_{t} e_{h}^{n}\right|_{1} k \\
& \leq \kappa\left|\phi\left(e_{h}^{n}\right)\right|_{1}^{1 / 2}\left(\left|\bar{e}_{h}^{n}\right|_{1}\left|e_{h}^{n}-e_{h}^{n-1}\right|_{1}^{1 / 2}+\left|\bar{e}_{h}^{n}\right|_{1}^{1 / 2}\left|e_{h}^{n}-e_{h}^{n-1}\right|_{1}\right) k \\
& \leq \kappa\left(\left|\bar{e}^{n}\right|_{1}^{2}+\left|e_{h}^{n-1}\right|_{1}^{2}+\left|e_{h}^{n-2}\right|_{1}^{2}\right) k .
\end{aligned}
$$

Combining these inequalities with (6.9) yields

$$
\begin{aligned}
& \nu\left(\left|e_{h}^{n}\right|_{1}^{2}-\left|e_{h}^{n-1}\right|_{1}^{2}\right)+\beta\left(\mathcal{C}_{h}\left(\mu_{h}^{n}, \mu_{h}^{n}\right)-\mathcal{C}_{h}\left(\mu_{h}^{n-1}, \mu_{h}^{n-1}\right)\right)+\left\|d_{t} e_{h}^{n}\right\|_{0}^{2} \tau_{0} \\
& \quad \leq \kappa\left(\left|e_{h}^{n-1}\right|_{1}^{2}+\left|e_{h}^{n-2}\right|_{1}^{2}\right) \tau_{0}+\kappa\left(\left|\bar{e}_{h}^{n}\right|_{1}^{2}+\left\|P_{h} E_{n}\right\|_{0}^{2}\right) \tau_{0}, \\
& \nu\left(\left|e_{h}^{n}\right|_{1}^{2}-\left|e_{h}^{n-1}\right|_{1}^{2}\right)+\beta\left(\mathcal{C}_{h}\left(\mu_{h}^{n}, \mu_{h}^{n}\right)-\mathcal{C}_{h}\left(\mu_{h}^{n-1}, \mu_{h}^{n-1}\right)\right)+\left\|d_{t} e_{h}^{n}\right\|_{0}^{2} \tau \\
& \quad \leq \kappa\left(\left|e_{h}^{n-1}\right|_{1}^{2}+\left|e_{h}^{n-2}\right|_{1}^{2}\right) \tau+\kappa\left(\left.||_{h}^{n}\right|_{1} ^{2}+\left\|P_{h} E_{n}\right\|_{0}^{2}\right) \tau,
\end{aligned}
$$

Summing (6.10) from $n=1$ to $n=m$ for $1 \leq m \leq n_{0}$ and summing (6.11) from $n=n_{0}+1$ to $n=m$ for $n_{0}+1 \leq m \leq N$, respectively, then using Lemmas 5.1 and 6.1 and Theorem 4.3 , we obtain

$$
\begin{aligned}
& \nu\left|e_{h}^{m}\right|_{1}^{2}+\beta \mathcal{C}_{h}\left(\mu_{h}^{m}, \mu_{h}^{m}\right)+\tau_{0} \sum_{n=1}^{m}\left\|d_{t} e_{h}^{n}\right\|_{0}^{2} \\
& \leq \kappa \tau_{0}+\kappa \tau_{0} \sum_{n=1}^{m-1}\left|e_{h}^{n}\right|_{1}^{2}, 1 \leq m \leq n_{0}, \\
& \nu\left|e_{h}^{m}\right|_{1}^{2}+\beta \mathcal{C}_{h}\left(\mu_{h}^{m}, \mu_{h}^{m}\right)+\tau_{0} \sum_{n=1}^{m}\left\|d_{t} e_{h}^{n}\right\|_{0}^{2} \\
& \leq \nu\left|e_{h}^{n_{0}}\right|_{1}^{2}+\beta \mathcal{C}_{h}\left(\mu_{h}^{n_{0}}, \mu_{h}^{n_{0}}\right)+\kappa \tau^{2}+\kappa \tau \sum_{n=n_{0}+1}^{m-1}\left|e_{h}^{n}\right|_{1}^{2}, n_{0}+1 \leq n \leq N .
\end{aligned}
$$

Applying Lemma 4.4 to (6.12) and 6.13), respectively, we obtain (6.6)-(6.7).

Lemma 6.3. Under the assumptions of Theorem 4.2, we have

$$
\begin{gathered}
\sigma\left(t_{m}\right)\left\|d_{t} e_{h}^{m}\right\|_{0}^{2} \leq \kappa \tau_{0}, \quad 1 \leq n \leq n_{0}, \\
\sigma\left(t_{m}\right)\left\|d_{t} e_{h}^{m}\right\|_{0}^{2} \leq \kappa \tau_{0}+\kappa \tau^{3 / 2}, \quad n_{0}+1 \leq n \leq N .
\end{gathered}
$$


Proof. From (5.3) we derive

$$
\begin{aligned}
& \frac{1}{k}\left(d_{t} e_{h}^{n}-d_{t} e_{h}^{n-1}, v_{h}\right)+\mathcal{B}_{h}\left(\left(d_{t} \bar{e}_{h}^{n}, d_{t} \tilde{\mu}_{h}^{n}\right) ;\left(v_{h}, q_{h}\right)\right) \\
&+b\left(\phi\left(d_{t} u_{h}^{n}\right), \bar{e}_{h}^{n}, v_{h}\right)+b\left(\phi\left(d_{t} u_{h}^{n-1}\right), d_{t} \bar{e}_{h}^{n}, v_{h}\right) \\
&+b\left(\phi\left(d_{t} e_{h}^{n}\right), \bar{u}_{h}\left(t_{n}\right), v_{h}\right)+b\left(\phi\left(e_{h}^{n-1}\right), d_{t} \bar{u}_{h}\left(t_{n}\right), v_{h}\right) \\
&=\left(d_{t} \tilde{E}_{n}, v_{h}\right)-\frac{\beta}{2 k^{2}} \int_{t_{n-1}}^{t_{n}}\left(t_{n}-t\right)\left(t-t_{n-1}\right) \mathcal{C}_{h}\left(p_{h t t}, q_{h}\right) d t \\
&-\frac{\beta}{2 k^{2}} \int_{t_{n-2}}^{t_{n-1}}\left(t_{n-1}-t\right)\left(t-t_{n-2}\right) \mathcal{C}_{h}\left(p_{h t t}, q_{h}\right) d t, \\
& \forall\left(v_{h}, q_{h}\right) \in\left(X_{h}, M_{h}\right),
\end{aligned}
$$

where we use the notation of $t_{-2}=t_{-1}=t_{0}$.

By setting $\left(v_{h}, q_{h}\right)=2\left(d_{t} \bar{e}_{h}^{n}, d_{t} \bar{\mu}_{h}^{n}\right) k$ in (6.16) and using (4.2), we obtain

$$
\begin{aligned}
\left\|d_{t} e_{h}^{n}\right\|_{0}^{2} & -\left\|d_{t} e_{h}^{n-1}\right\|_{0}^{2}+2\left(\nu\left|d_{t} \bar{e}_{h}^{n}\right|_{1}^{2}+\beta \mathcal{C}_{h}\left(d_{t} \tilde{\mu}_{h}^{n}, d_{t} \tilde{\mu}_{h}^{n}\right)\right) k \\
& +-2 b\left(\phi\left(d_{t} e_{h}^{n}\right), \bar{e}_{h}^{n}, d_{t} \bar{e}_{h}^{n}\right) k+2 b\left(\phi\left(d_{t} e_{h}^{n}\right), \bar{u}_{h}\left(t_{n}\right), d_{t} \bar{e}_{h}^{n}\right) \\
& +2 b\left(\phi\left(d_{t} u_{h}\left(t_{n}\right)\right), \bar{e}_{h}^{n}, d_{t} \bar{e}_{h}^{n}\right) k+2 b\left(\phi\left(e_{h}^{n-1}\right), d_{t} \bar{u}_{h}\left(t_{n}\right), d_{t} \bar{e}_{h}^{n}\right) k \\
= & 2\left(d_{t} \tilde{E}_{n}, d_{t} \bar{e}_{h}^{n}\right) k-\frac{\beta}{2 k} \int_{t_{n-1}}^{t_{n}}\left(t_{n}-t\right)\left(t-t_{n-1}\right) \mathcal{C}_{h}\left(p_{h t t}, d_{t} \tilde{\mu}_{h}^{n}\right) d t \\
& -\frac{\beta}{2 k} \int_{t_{n-2}}^{t_{n-1}}\left(t_{n-1}-t\right)\left(t-t_{n-2}\right) \mathcal{C}_{h}\left(p_{h t t}, d_{t} \tilde{\mu}_{h}^{n}\right) d t .
\end{aligned}
$$

Then, a simple calculation, using (4.1)-(4.4), Theorem 4.3 and Lemmas 6.1 and 6.2, yields

$$
\begin{aligned}
2\left|b\left(\phi\left(d_{t} e_{h}^{n}\right), \bar{e}_{h}^{n}, d_{t} \bar{e}_{h}^{n}\right)\right| k & \leq 2 c_{0} \gamma_{0}\left|\phi\left(d_{t} e_{h}^{n}\right)\right|_{1}\left|\bar{e}_{h}^{n}\right|_{1}\left|d_{t} \bar{e}_{h}^{n}\right|_{1} k \\
& \leq \frac{\nu}{4}\left|d_{t} \bar{e}_{h}^{n}\right|_{1}^{2} k+4 \nu^{-1} c_{0}^{2} \gamma_{0}^{2}\left|\phi\left(e_{h}^{n}-e_{h}^{n-1}\right)\right|_{1}^{2}\left|\bar{e}_{h}^{n}\right|_{1}^{2} k^{-1}, \\
2\left|b\left(\phi\left(e_{h}^{n-1}\right), d_{t} \bar{u}_{h}\left(t_{n}\right), d_{t} \bar{e}_{h}^{n}\right)\right| k & \leq 2 c_{0} \gamma_{0}\left|\phi\left(e_{h}^{n-1}\right)\right|_{1}\left|d_{t} \bar{u}_{h}\left(t_{n}\right)\right|_{1}\left|d_{t} \bar{e}_{h}^{n}\right|_{1} k \\
& \leq \frac{\nu}{4}\left|d_{t} \bar{e}_{h}^{n}\right|_{1}^{2} k+4 \nu^{-1} c_{0}^{2} \gamma_{0}^{2} \int_{t_{n-2}}^{t_{n}}\left|u_{h t}\right|_{1}^{2} d t\left|\phi\left(e_{h}^{n-1}\right)\right|_{1}^{2}, \\
2\left|b\left(\phi\left(d_{t} u_{h}\left(t_{n}\right)\right), \bar{e}_{h}^{n}, d_{t} \bar{e}_{h}^{n}\right)\right| k & \leq 2 c_{0} \gamma_{0}\left|\phi\left(d_{t} u_{h}\left(t_{n}\right)\right)\right|_{1}\left|\bar{e}_{h}^{n}\right|_{1}\left|d_{t} \bar{e}_{h}^{n}\right|_{1} k \\
& \leq \frac{\nu}{4}\left|d_{t} \bar{e}_{h}^{n}\right|_{1}^{2} k+5 \nu^{-1} c_{0}^{2} \gamma_{0}^{2} \int_{t_{n-3}}^{t_{n-1}}\left|u_{h t}\right|_{1}^{2} d t\left|\bar{e}_{h}^{n}\right|_{1}^{2}, \\
2\left|b\left(\phi\left(d_{t} e_{h}^{n}\right), \bar{u}_{h}\left(t_{n}\right), d_{t} \bar{e}_{h}^{n}\right)\right| k & \leq 2 c_{0} \gamma_{0}\left\|\phi\left(d_{t} e_{h}^{n}\right)\right\|\left\|_{0}\right\| A_{h} \bar{u}_{h}\left(t_{n}\right) \|_{0}\left|d_{t} \bar{e}_{h}^{n}\right|_{1} k \\
& \leq \frac{\nu}{4}\left|d_{t} \bar{e}_{h}^{n}\right|_{1}^{2} k+4 \nu^{-1} c_{0}^{2} \gamma_{0}^{2}\left\|\phi\left(d_{t} e_{h}^{n}\right)\right\|_{0}^{2}\left\|A_{h} \bar{u}_{h}\left(t_{n}\right)\right\|_{0}^{2} k,
\end{aligned}
$$




$$
\begin{aligned}
2\left|\left(d_{t} E_{n}, d_{t} \bar{e}_{h}^{n}\right)\right| k \leq \frac{\nu}{4}\left|d_{t} \bar{e}_{h}^{n}\right|_{1}^{2} k+8 \nu^{-1}\left(\left\|A_{h}^{-1 / 2} P_{h} E_{n}\right\|_{0}^{2}\right. & \left.+\left\|A_{h}^{-1 / 2} P_{h} E_{n-1}\right\|_{0}^{2}\right) k^{-1}, \\
\frac{\beta}{2 k}\left|\int_{t_{n-1}}^{t_{n}}\left(t_{n}-t\right)\left(t-t_{n-1}\right) \mathcal{C}_{h}\left(p_{h t t}, d_{t} \tilde{\mu}_{h}^{n}\right) d t\right| & \leq \frac{\beta}{2} \mathcal{C}_{h}\left(d_{t} \tilde{\mu}_{h}^{n}, d_{t} \tilde{\mu}_{h}^{n}\right) k \\
+ & \frac{\beta}{8 k^{2}} \int_{t_{n-1}}^{t_{n}}\left(t_{n}-t\right)^{2}\left(t-t_{n-1}\right)^{2} \mathcal{C}_{h}\left(p_{h t t}, p_{h t t}\right) d t, \\
\frac{\beta}{2 k} \mid \int_{t_{n-2}}^{t_{n-1}}\left(t_{n-1}-t\right)(t & \left.-t_{n-2}\right) \mathcal{C}_{h}\left(p_{h t t}, d_{t} \tilde{\mu}_{h}^{n}\right) d t \mid \leq \frac{\beta}{2} \mathcal{C}_{h}\left(d_{t} \tilde{\mu}_{h}^{n}, d_{t} \tilde{\mu}_{h}^{n}\right) k \\
+ & \frac{\beta}{8 k^{2}} \int_{t_{n-2}}^{t_{n-1}}\left(t_{n-1}-t\right)^{2}\left(t-t_{n-2}\right)^{2} \mathcal{C}_{h}\left(p_{h t t}, p_{h t t}\right) d t,
\end{aligned}
$$

for all $2 \leq n \leq N$.

Combining these inequalities with (6.17) and using (5.13) yields

$$
\begin{aligned}
& \sigma\left(t_{n}\right)\left\|d_{t} e_{h}^{n}\right\|_{0}^{2}-\sigma\left(t_{n-1}\right)\left\|d_{t} e_{h}^{n-1}\right\|_{0}^{2} \leq\left\|d_{t} e_{h}^{n-1}\right\|_{0}^{2} k \\
& +8 \nu^{-1}\left(\sigma\left(t_{n}\right)\left\|A_{h}^{-1 / 2} P_{h} E_{n}\right\|_{0}^{2}+2 \sigma\left(t_{n-1}\right)\left\|A_{h}^{-1 / 2} P_{h} E_{n-1}\right\|_{0}^{2}\right) k^{-1} \\
& +4 \nu^{-1} c_{0}^{2} \gamma_{0}^{2}\left|\phi\left(e_{h}^{n}-e_{h}^{n-1}\right)\right|_{1}^{2}\left|\bar{e}_{h}^{n}\right|_{1}^{2} k^{-1}+4 \nu^{-1} c_{0}^{2} \gamma_{0}^{2} \int_{t_{n-2}}^{t_{n}}\left|u_{h t}\right|_{1}^{2} d t\left|\phi\left(e_{h}^{n-1}\right)\right|_{1}^{2} \\
& +5 \nu^{-1} c_{0}^{2} \gamma_{0}^{2} \int_{t_{n-3}}^{t_{n-1}}\left|u_{h t}\right|_{1}^{2} d t\left|\bar{e}_{h}^{n}\right|_{1}^{2}+4 \nu^{-1} c_{0}^{2} \gamma_{0}^{2}\left\|\phi\left(d_{t} e_{h}^{n}\right)\right\|_{0}^{2}\left\|A_{h} \bar{u}_{h}\left(t_{n}\right)\right\|_{0}^{2} k \\
& +\frac{\beta}{4} k \int_{t_{n-1}}^{t_{n}}\left(t-t_{n-1}\right) \sigma(t) \mathcal{C}_{h}\left(p_{h t t}, p_{h t t}\right) d t \\
& +\frac{\beta}{4} k \int_{t_{n-2}}^{t_{n-1}}\left(t-t_{n-2}\right) \sigma(t) \mathcal{C}_{h}\left(p_{h t t}, p_{h t t}\right) d t .
\end{aligned}
$$

Summing (6.18) from $n=1$ to $n=m$ for $1 \leq m \leq n_{0}$ and (6.18) from $n=n_{0}+1$ to $n=m$ for $n_{0}+1 \leq m \leq N$, then using Lemmas 5.1, 6.1, and 6.2, and Theorem 4.3 and noting $\sigma^{-1}\left(t_{n-1}\right) \leq t_{n_{0}}^{-1}=\tau^{-1 / 2}$ for all $n_{0}+1 \leq n \leq N$, we obtain (6.14) and (6.15).

Lemma 6.4. Under the assumptions of Theorem 4.2, the error $\bar{\mu}^{m}=\bar{p}\left(t_{m}\right)-\bar{p}_{h}^{m}$ satisfies the bound

$$
\sigma^{1 / 2}\left(t_{m}\right)\left\|\bar{p}_{h}\left(t_{m}\right)-\bar{p}_{h}^{m}\right\|_{0} \leq \kappa \tau_{0}^{1 / 2}+\kappa \tau^{3 / 4}, 1 \leq m \leq N
$$

Proof. First, we derive from (5.4) and Theorem 3.2 that

$$
\begin{aligned}
\sigma^{1 / 2}\left(t_{m}\right)\left\|\bar{\mu}_{h}^{m}\right\|_{0} & \leq c\left|\bar{e}_{h}^{m}\right|_{1}+c\left\|d_{t} e_{h}^{m}\right\|_{0}+c\left|\phi\left(e_{h}^{m}\right)\right|_{1}\left|u_{h}\left(t_{m}\right)\right|_{1}+c\left|\phi\left(u_{h}\left(t_{m}\right)\right)\right|_{1}\left|\bar{e}_{h}^{m}\right|_{1} \\
& +c\left|\phi\left(e_{h}^{m}\right)\right|_{1}\left|\bar{e}_{h}^{m}\right|_{1}+c \sigma^{1 / 2}\left(t_{m}\right)\left\|E_{m}\right\|_{0}, 1 \leq m \leq N .
\end{aligned}
$$

Then, by using Theorem 4.3 and Lemmas 6.2, 6.3, and 5.1 in the above estimate, we obtain

$$
\begin{aligned}
\sigma^{1 / 2}\left(t_{m}\right)\left\|\bar{\mu}_{h}^{m}\right\|_{0} & \leq \kappa\left(\left|\bar{e}_{h}^{m}\right|_{1}+\left|\phi\left(e_{h}^{m}\right)\right|_{1}+\sigma^{1 / 2}\left(t_{m}\right)\left\|d_{t} e_{h}^{m}\right\|_{0}\right)+c \sigma^{1 / 2}\left(t_{m}\right)\left\|E_{m}\right\|_{0} \\
(6.20) & \leq \kappa \tau_{0}^{1 / 2}+\kappa \tau^{3 / 4}, 1 \leq m \leq N
\end{aligned}
$$

which is (6.19). 
Theorem 6.5. Under the assumptions of Theorem 4.2, the error $\left(e^{m}, \bar{\mu}^{m}\right)=$ $\left(u\left(t_{m}\right)-u_{h}^{m}, \bar{p}\left(t_{m}\right)-\bar{p}_{h}^{m}\right)$ satisfies the bound

$$
\begin{aligned}
& \left\|u\left(t_{m}\right)-u_{h}^{m}\right\|_{0} \leq \kappa\left(h^{2}+\tau^{3 / 2}\right), \\
& \left\|u\left(t_{m}\right)-u_{h}^{m}\right\|_{1} \leq\left(h+\tau^{3 / 4}\right), \sigma^{1 / 2}\left(t_{m}\right)\left\|\bar{p}\left(t_{m}\right)-\bar{p}_{h}^{m}\right\|_{0} \leq \kappa\left(h+\tau^{3 / 4}\right),
\end{aligned}
$$

for all $t_{m} \in(0, T]$.

Proof. By combining Lemmas 6.1, 6.2, and 6.4 with Theorem 4.2 and noting that $\tau_{0}=\frac{1}{T} \tau^{3 / 2}$, completes the proof of Theorem 6.5.

Remark. We have presented the convergence analysis of a stabilized finite element method with the Crank-Nicolson extrapolation scheme in time direction for the two-dimensional time-dependent Navier-Stokes problem. We have proved that the scheme is unconditionally stable. However, the error estimate obtained in this paper is not optimal in time direction, which is mainly for lack of discrete Stokes operator on the finite element space pair $\left(X_{h}, M_{h}\right)$ by the $Q_{1}-P_{0}$ quadrilateral element or the $P_{1}-P_{0}$ triangle element. In this case, the estimate

$$
\tau \sum_{n=1}^{N}\left\|\bar{u}_{h}\left(t_{n}\right)-\bar{u}_{h}^{n}\right\|_{-1}^{2} \leq \kappa \tau^{4}
$$

used in 28] is no longer available.

\section{ACKNOWLEDGMENTS}

The authors would like to thank the editor and referees for their valuable comments and suggestions which helped to improve the results of this paper.

\section{REFERENCES}

1. R. A. Adams, Sobolev Spaces, Academic press, New York, 1975. MR 0450957 (56:9247)

2. A. Agouzal, A Posteriori error estimator for finite element discretizations of quasi-Newtonian flows, Int. J. Numer. Anal. \& Modeling, 2(2005), pp. 221-239. MR.2111749 (2006b:76045)

3. A. Ait $\mathrm{Ou}$ Ammi and M. Marion, Nonlinear Galerkin methods and mixed finite elements: Two-grid algorithms for the Navier-Stokes equations, Numer. Math., 68 (1994), pp. 189-213. MR.1283337 (95c:65174)

4. I. Babuška, J. Osborn and J. Pitkaranta, Analysis of mixed methods using mesh dependent norms, Math. Comp., 35(1980), pp. 1039-1062. MR0583486 (81m:65166)

5. G. A. Baker, V. A. Dougalis and O. A. Karakashian, On a high order accurate fully discrete Galerkin approximation to the Navier-Stokes equations, Math. Comp., 39(1982), pp. 339-375. MR0669634 (84h:65096)

6. J. Bercovier and O. Pironneau, Error estimates for finite element solution of the Stokes problem in the primitive variables, Numer. Math., 33(1979), pp. 211-226. MR0549450(81g:65145)

7. C. Bernardi and G. Raugel, A conforming finite element method for the time-dependent the Navier-Stokes equations, SIAM J. Numer. Anal., 22(1985), pp. 455-473. MR0787570 (86j:65128)

8. J. Boland and R. A. Nicolaides, Stability of finite elements under divergence constraints, SIAM J. Numer. Anal., 20(1983), 722-731. MR0708453 (85e:65046)

9. K. Boukir, Y. Maday, B. Métivet and E. Razafindrakoto, A high-order characteristics/finite element method for the incompressible Navier-Stokes equations, Int. J. Numer. Methods for Fluids, 25(1997), pp. 1421-1454. MR.1601529 (99a:76082)

10. J. H. Bramble and J. E. Pasciak, A preconditioning technique for indefinite systems resulting from mixed approximations of elliptic problems, Math. Comp., 50(1988), pp. 1-17. MR0917816 (89m:65097a)

11. J. H. Bramble and J. $\mathrm{Xu}$, Some estimates for a weighted $L^{2}$ projection, Math. Comp., 56(1991), pp. 463-576. MR.1066830 (91k:65140) 
12. F. Brezzi and J. Pitkäranta, On the stabilisation of finite element approximations of the Stokes problems, Efficient Solutions of Elliptic Systems (W. Hackbusch, ed.), Notes on Numerical Fluid Mechanics, Vol. 10, Vieweg, Braunschweig, 1984, pp. 11-19. MR0804083 (86j:65147)

13. P. G. Ciarlet, The Finite Element Method for Elliptic Problems, North-Holland, Amsterdam, 1978. MR0520174(58:25001)

14. J. Douglas, Jr. and T. Dupont, Galerkin methods for parabolic equations, SIAM J. Numer. Anal., 7(1970), pp. 575-626. MR0277126 (43:2863)

15. J. Douglas, Jr. and J. Wang, A absolutely stabilized finite element method for the Stokes problem, Math. Comp., 52(1989), pp. 495-508. MR0958871 (89j:65069)

16. T. Dupont, G. Fairweather and J. P.Johnson, Three-level Galerkin methods for parabolic equations, SIAM J. Numer. Anal., 11(1974), pp. 392-410. MR0403259 (53:7071)

17. H. Elman and D. Silvester, Fast nonsymmetric interations and preconditioning for NavierStokes equations, SIAM J. Scientific Comput., 17(1996), pp. 33-76. MR1375264 (97e:65119)

18. V. Girault and P. A. Raviart, Finite Element Method for Navier-Stokes Equations: theory and algorithms, Springer-Verlag, Berlin, Heidelberg 1987. MR0851383 (88b:65129)

19. J. L. Guermond and J. Shen, Velocity-correction projection methods for incompressible flows, SIAM J. Numer. Anal., 41(2003), pp. 112-134. MR1974494 (2004c:65103)

20. Yinnian He, Stability and error analysis for a spectral Galerkin method for the Navier-Stokes equations with $H^{2}$ or $H^{1}$ initial data, Numer. Methods for Partial Differential Equations, 21 (2005), pp. 875-904. MR2154224 (2006d:65108)

21. Yinnian He, A fully discrete stabilized finite element method for the time-dependent NavierStokes problem, IMA J. Numer. Anal., 23(2003), pp 665-691. MR2011345 (2004m:65151)

22. Yinnian He, Two-level method based on finite element and Crank-Nicolson extrapolation for the time-dependent Navier-Stokes equations, SIAM J. Numer. Anal., 41(2003), pp. 1263-1285. MR2034880 (2004k:65173)

23. Yinnian He and K. M. Liu, A multi-level finite element method for the time-dependent NavierStokes equations, Numer. Methods for Partial Differential Equations, 21(2005), pp. 1052-1068. MR 2169167

24. Yinnian He, Aiwen Wang and Liqun Mei, Stabilized finite element method for the stationary Navier-Stokes equations, J. Engineering Mathematics, 51(2005), pp. 367-380. MR2146399 (2006a:65161)

25. Yinnian $\mathrm{He}$ and Kaitai Li, Convergence and stability of finite element nonlinear Galerkin method for the Navier-Stokes equations, Numer. Math., 79(1998), pp. 77-107. MR1608417 (99c:65165)

26. Yinnian He, Yanping Lin and Weiwei Sun, Stabilized finite element method for the NavierStokes problem, Discrete Contin. Dyn. Syst. series-B, 6(2006), pp. 41-68. MR2172195

27. J. G. Heywood and R. Rannacher, Finite element approximation of the nonstationary NavierStokes problem I: Regularity of solutions and second-order error estimates for spatial discretization, SIAM J. Numer. Anal., 19(1982), pp. 275-311. MR0650052 (83d:65260)

28. J. G. Heywood and R. Rannacher, Finite element approximation of the nonstationary NavierStokes problem IV: Error Analysis for second-order time discretization, SIAM J. Numer. Anal., 27(1990), pp. 353-384. MR1043610 (92c:65133)

29. A. T. Hill and E. Süli, Approximation of the global attractor for the incompressible NavierStokes equations, IMA J. Numer. Anal., 20(2000), pp. 633-667. MR.1795301 (2001j:37138)

30. Kaitai $\mathrm{Li}$ and Yinnian He, Taylor expansion algorithm for the branching solution of the Navier-Stokes equations, Int. J. Numer. Anal. \& Modeling, 2(2005), pp. 459-478. MR 2177873

31. R. B. Kellogg and J. E. Osborn, A regularity result for the Stokes problem in a convex polygon, J. Funct. Anal., 21(1976), pp. 397-431. MR0404849 (53:8649)

32. D. Kay and D. Silvester, A posteriori error estimation for stabilized mixed approximations of the Stokes equations, SIAM J. Sci. Comput., 21(2000), pp. 1321-1337. MR1740398 (2000m:65130)

33. N. Kechkar and D. Silvester, Analysis of locally stabilized mixed finite element methods for the Stokes problem, Math. Comp., 58(1992), pp. 1-10. MR.1106973 (92e:65138)

34. S. Larsson, The long-time behavior of finite-element approximations of solutions to semilinear parabolic problems, SIAM J. Numer. Anal., 26(1989), pp. 348-365. MR0987394 (90g:65124)

35. M. Marion and J. Xu, Error estimates on a new nonlinear Galerkin method based on two-grid finite elements, SIAM J. Numer. Anal., 32(1995), pp. 1170-1186. MR1342288 (96f:65136) 
36. S. Norburn and D. Silvester, Stabilised vs stable mixed methods for incompressible flow, Comput. Methods Appl. Mech. Engrg., 166(1998), pp.1-10. MR.1660188(99i:76090)

37. J. Pitkäranta and T. Saarinen, A multigrid version of a simple finite element method for the Stokes problem, Math. Comput., 45(1985), pp. 1-14. MR0790640 (86h:65168)

38. R. L. Sani, P. M. Gresho, R. L. Lee and D. F. Griffiths, The cause and cure(?) of the spuious pressures generated by certain finite element method solutions of the incompressible Navier-Stokes equations, Parts 1 and 2, Internat J. Numer. Methods Fluids 1(1981), pp. 17-43; pp. 171-206. MR0608691 (83i:65083a) MR0621064 (83i:65083b)

39. J. Shen, Long time stability and convergence for fully discrete nonlinear Galerkin methods, Applicable Analysis, 38(1990), pp. 201-229. MR.1116181 (93a:65130)

40. J. Shen, On error estimates of the projection methods for Navier-Stokes equations: Second order schemes, Math Comp., 65(1996), pp. 1039-1065. MR1348047 (96j:65091)

41. D. Silvester and A. Wathen, Fast iterative solution of stabilised Stokes systems, Part II: Using general block preconditioners, SIAM J. Numer. Anal., 31(1994), pp. 1352-1367. MR1293519 (95g:65132)

42. D. J. Silvester and N. Kechkar, Stabilised bilinear-constant velocity-pressure finite elements for the conjugate gradient solution of the Stokes problem, Comput. Methods Appl. Mech. Engrg., 79(1990), pp. 71-87. MR.1044204 (90m:76011)

43. R. Stenberg, Analysis of mixed finite elements for the Stokes problem: A unified approach, Math. Comp., 42(1984), pp 9-23. MR0725982 (84k:76014)

44. E. Süli, Convergence and nonlinear stability of the Lagrange-Galerkin method for the NavierStokes equations, Numer. Math., 53(1988), pp. 459-484. MR0951325 (90b:65214)

45. R. Temam, Navier-Stokes Equations, Theory and Numerical Analysis, Third ed., NorthHolland, Amsterdam, 1983. MR0769654 (86m:76003)

46. R. Verfürth, A multilevel algorithm for mixed problems, SIAM J. Numer. Anal., 21(1984), pp. 264-271. MR0736330 (85f:65112)

47. J. Xu, A novel two-grid method for semilinear elliptic equations, SIAM J. Sci. Comput.,15(1994), pp. 231-237. MR1257166 (94m:65178)

48. J. Xu, Two-grid discretization techniques for linear and nonlinear PDEs, SIAM J. Numer. Anal., 33(1996), pp. 1759-1778. MR1411848(97i:65169)

Faculty of Science, Xi'an Jiaotong University, Xi'an 710049, People's Republic of CHINA

E-mail address: heyn@mail.xjtu.edu.cn

Department of Mathematics, City University of Hong Kong, Hong Kong, People's RePublic OF China

E-mail address: maweiw@math.cityu.edu.hk 